F. med. Genet. (1967). 4, 190.

\title{
Determinants of Sex Proportions in Man, with Consideration of the Evidence Concerning a Contribution from X-Linked Mutations to Intrauterine Death
}

\author{
ALAN C. STEVENSON and MARTIN BOBROW
}

\author{
From the Medical Research Council, Population Genetics Research Unit, Old Road, Headington, Oxford
}

Many attempts have been made to explain the slight preponderance of male live births in human populations. Recognition of the role of the sex chromosomes in sex determination and of the segregation mechanisms involved suggested that the primary sex ratio (i.e. the relative numbers of male and female zygotes) should be equality, and there has been much speculation as to how this could be reconciled with the excess of live born males. Further difficulties in this reconciliation arose when it was recognized that there was also an excess of males among foetuses dying in utero, and that this was even greater than that existing among live births.

Conventionally, a sex ratio is the number of males divided by the number of females, whereas a sex proportion is the number of males divided by the number of males plus the number of females. 'Sex ratio' is, however, frequently used to describe what are, in fact, sex proportions. It is a matter of convenience which index is used, as for statistical treatment either may be the more appropriate.

Many writers have suggested that the occurrence of recessive lethal mutations on the $\mathrm{X}$ chromosomes, by causing the death in utero of hemizygous males, could explain in whole or in part the unequal prenatal losses of the two sexes. It was, therefore, inevitable that hypotheses involving X-linked lethal mutations should be advanced when disturbances of sex ratios were found in infants born to parents previously exposed to ionizing radiation. Although these shifts in sex ratios were small and not entirely convincing, they were the only observed changes in the offspring of irradiated parents in Hiroshima and Nagasaki (Neel and Schull, 1956) and in those of parents who had received therapeutic irradiation (Turpin, Lejeune, and Rethore, 1956). Further, in both instances and in subse- quent data studied by Scholte and Sobels (1964) the effects appeared to be in the same direction, viz. a reduction in the sex ratio of the children of exposed mothers and (less impressively or consistently) an increase in the ratio amongst children of exposed fathers.

Starting from the hypothesis that these changes were due to $\mathrm{X}$-linked lethal genes of varying degrees of dominance, estimates have been made of the rates of induction of such mutations for given radiation doses. Estimates have similarly been made of supposed spontaneous mutation rates to recessive lethals acting in utero over the whole of the $\mathrm{X}$ chromosome in man. By extension, and on the assumption that mutations occur in approximate proportion to chromosome length, estimates have also been made of a total mutation rate over the entire human genome. Indeed, figures so derived form the basis of one of the main estimates of the genetic risks of radiation in the latest report of the United Nations Scientific Committee on the Effects of Atomic Radiation (UNSCEAR) (United Nations, 1966).

It will thus be seen that the study of sex ratios, apart from its intrinsic biological interest, has acquired added importance through its common use as a method of estimating mutation rates, both spontaneous and induced, and as a possible index of the genetic detriment caused to the species by mutagenic agents such as irradiation. In view of the great difficulties inherent in other approaches to measuring mutation rates in man, and the relative ease with which vast amounts of data on sex ratios may be accumulated, it is understandable that such calculations should be made. Although it is not difficult to criticize them, there do not at present appear to be other approaches to estimates of total 
mutation rates in man based on human data, which are not open to just as serious objections.

Most of the early experimental work on quantitative aspects of spontaneous and induced mutations was on X-linked recessive mutations in drosophilamainly Drosophila melanogaster. Drosophila is particularly well suited to the study of this problem, as the $\mathrm{X}$ chromosome contributes about one-third of the total length of the haploid set of chromosomes, and the well-known techniques using $\mathrm{X}$ chromosomes with visible gene markers, and an inversion to prevent crossing-over in females, have enabled large numbers of $\mathrm{X}$ chromosomes to be screened for newly-arisen lethal mutations. Furthermore, as with any experimental animal, the background genotypes and environmental influences can be far more closely controlled than is possible in man, and as both of these undoubtedly can influence secondary sex ratios, much more precise observations can be made.

When writers present evidence for the occurrence of X-linked mutations in man and proceed to try to estimate their numbers and mutation rates in various forms, they seldom have space to review adequately the other factors which, by influencing sex ratios, may simulate the effects of $\mathrm{X}$-linked mutations. The evidence on these matters comes from work published in a variety of journals and does not appear to have been considered as a whole. Writers also appear to use sex ratios or proportions almost exclusively as the indicator on which calculations relating to $\mathrm{X}$-linked mutations are based. There can be little doubt that these indices have been misused. Later in the text several examples are cited where relative mortalities in the sexes are more relevant.

It is proposed to review the literature on known factors which influence such indices in man, and on evidence on the same subject from experimental animals. In the light of these it is possible to examine more closely the validity of calculations which purport to result in measures of the detriment acting in utero, determined by mutations on the $\mathrm{X}$ chromosome in man.

\section{1: VARIATION OF SECONDARY SEX RATIOS IN MAN}

\section{1: Determinants of Live Birth Sex Ratios}

The constant excess of males born in all large populations and possible explanations of secular, racial, and environmental variations in the degree of male preponderance have been considered in many publications. From reports of National Statistical Offices all over the world huge amounts of simple data on numbers of live and stillbirths are available, and these have been used to study secular trends, racial and geographic frequencies, and the relationships of sex ratios of live and stillbirths to parental ages and birth orders.

Sex ratios and the sex proportions are often used without sufficient consideration being given to their significance, and this is particularly so when changes in the value of the index are under consideration. The nature of a ratio or proportion is such that its value will change when there is alteration in values of either or both of the two compared variables, unless the amount of change in each is by the same factor of the preceding value. Unless one variable can be regarded as constant, changes in the other cannot therefore be estimated.

The sex ratio of live births is that of a population of survivors, and must depend on that of the original population of zygotes (the primary sex ratio) and on subsequent differential losses in utero by sex. It is convenient to group such losses sequentially as failure to implant, implantation but early death and resorption, which will be called implantation losses, subsequent losses of concepti which last long enough to cause recognizable abortions (up to the end of the 27th week of pregnancy), and stillbirths (foetuses of 28 weeks' gestational age and over which are born dead).

It follows, from the above considerations, that the sex ratio of stillbirths is not necessarily an index of the relative stillbirth rates in the sexes (conventionally the number of stillbirths per 1000 live + stillbirths). Indeed, the ratio of stillbirth rates in the sexes and the sex ratio of stillbirths will only be the same in the specific circumstances outlined below. This simple point is important because, as will later be discussed, many writers have used stillbirth or live birth sex ratios and their variations as indices of male mortality.

If $M_{t}$ and $F_{t}$ are the numbers of males and females in utero at the beginning of the 28th week of pregnancy, and $M_{d}$ and $F_{d}, M_{1}$ and $F_{1}$ are the numbers of male and female stillbirths and live births, then $M_{t}=M_{1}+M_{d}$ and $F_{t}=F_{1}+F_{d}$. The stillbirth rates by sex are then $\frac{M_{d}}{M_{t}}$ and $\frac{F_{d}}{F_{t}}$, and the sex ratios of live births and stillbirths are $\frac{M_{1}}{F_{1}}$ and $\frac{M_{d}}{F_{d}}$. The ratio of mortalities is therefore $\frac{M_{d}}{M_{t}} / \frac{F_{d}}{F_{t}}=\frac{M_{d}}{M_{t}} \times \frac{F_{t}}{F_{d}}=\frac{M_{d}}{F_{d}} \times \frac{F_{t}}{M_{t}}$, and is therefore the stillbirth sex ratio multiplied by the reciprocal of the sex ratio of total births.

$$
\text { Male mortality is } \frac{M_{d}}{M_{t}} \text { and the stillbirth sex ratio } \frac{M_{d}}{F_{d}} \text { so }
$$
that the sex ratio of stillbirths is not equivalent to male mortality but to that mortality multiplied by the number of males in utero at 28 weeks, divided by the number of female stillbirths $\left(\frac{M_{d}}{F_{d}}=\frac{M_{d}}{M_{t}} \times \frac{M_{t}}{F_{d}}\right)$. These points 
are of particular importance when considering evidence on excess male over female mortality, whether attributed to genetic or to other causes. If data are available, however, on live and stillbirths by sex in large populations, it is always possible to calculate the number in utero at 28 weeks and stillbirth rates by sex, so avoiding the limitations of use of sex ratios.

It has also to be remembered that mortality in females is not necessarily independent of variation of the portion of male mortality caused by X-linked mutations. Such mutations are unlikely to be fully recessive, and twice as many will be received in each generation by females as by males. Thus, even if the probability of death which they confer in females is only a few per cent of that determined in hemizygous males, any change in mortality in males caused by X-linked mutations will be paralleled in females by smaller shifts in the same direction.

\section{2: Ethnic Origins}

There is some evidence of differences in live birth sex ratios in peoples of varying ethnic origins, as is clear from the values tabulated in United Nations Demographic Year Book (1959) and other published data. However, in those countries where the data are considered to be reliable by the United Nations Statistical Department, the observed differences are not large. In all these populations there is an excess of male live births but a few small communities have been described where the sex proportion is just less than 0.5. Ciocco (1938) concludes that in the United States the sex ratio is smaller in people of African than in those of European origins.

\section{3: Changes Over Time of Live Birth Sex Ratios}

Changes over time in the same population have often been observed, but they have not been satisfactorily related to the variables which spring to mind as likely to be causative, such as changes in ages at marriage, parental ages, or marked changes in stillbirth rates. There has been periodic interest in a possible rise in sex ratio of live births in large populations during and after major wars (Russell, 1936; Ciocco, 1938; McMahon and Pugh, 1954). Again this phenomenon has not been satisfactorily related to the obvious variables.

\section{4: Socio-economic Influences}

Crew (1948) and others have suggested that the sex proportion of live births reflects environmental conditions in communities studied and should increase with improving socio-economic conditions. It was argued that as there was an excess mortality in males in utero, when such deaths become less frequent relatively more males would survive to be born alive. Whether or not such a change would result in an increase in the live birth sex ratio would, however, depend on whether or not the relative foetal mortalities in the two sexes fell with improving conditions by the same proportions of previous mortalities in each sex, or both fell by the same proportion of the previous combined mortalities, as may be seen from the 'models' considered later (Section 4.2).

Few relevant analyses of data to test such hypotheses appear to have been made, however (Section 4.1), and evidence that there are any differences in live birth sex ratio in the offspring of rich and poor in the same communities is scanty and inconclusive.

\section{5: Seasonal Variation}

Seasonal variations in sex proportions have been noted in large bodies of data. For example, Slatis (1953) by analysis of United States birth data from 1915-1948 found the highest sex proportion of live births during the May to July quarter of the year and the lowest in October to March. However, as so often with sex ratio data the pattern is not simple and January births were consistently very high. In Slatis's data there appeared to be no differences in any discernible seasonal trends between rural and urban communities. Ciocco (1938) noted the same type of seasonal fluctuation in United States data (which included most of that used by Slatis) but was not convinced that the variation found was statistically significant. Ciocco also failed to find relationships of the sex ratio to climatic and geographic factors within the United States, though there was some suggestion from Slatis's analyses that these had some effect.

\section{6: ABO Blood Groups and Sex Ratios of Live Births}

There has been considerable interest in possible relationships between the sex ratio of live births and the $\mathrm{ABO}$ blood group phenotypes of parents and infants. Hirszfeld and Zborowski (1925) in a small sample of 264 births concluded that there was a lower sex proportion in offspring of $\mathrm{AB}$ mothers, but Allan (1955) and Cohen and Glass (1956) could not confirm this finding. Sanghvi (1951) concluded from data from Bombay and New York that the sex proportion of $\mathrm{O}$ group infants born to $\mathrm{O}$ mothers was higher than A group infants born to A mothers. The data of Allan (1958) and Shield, Kirk, and Jakobowicz (1958) appeared, however, to support the original findings of Hirszfeld and Zborowski (1925) and also the observations of Sanghvi (1951). The father/child $\mathrm{ABO}$ blood group combinations reviewed by Cohen and Glass (1956) and Allan 
(1959) did not reveal statistically significant differences in sex ratios.

Waterhouse and Hogben (1947) suggested that there was a deficiency in A group children of both sexes born to $O$ group mothers, and that this was explicable in terms of loss by abortion of A group concepti to $O$ group mothers due to anti-A agglutinins in the mother. Cohen and Glass (1959), in a further review, considered the findings in large sets of data in which the child had an $A B O$ group antigen 'foreign' to the mother, but could not demonstrate significant differences in the sex proportions between 'compatible' and 'incompatible' contributions.

Edwards (1957) in a critical review of the literature pointed to the extreme difficulties of statistical analysis and interpretation of association of blood group phenotypes with observed differences in man and in particular with such difficult variables as sex ratio and fertility. He stressed in particular the large sampling errors of most data and the frequency of technical errors in grouping, specifically AB subjects often being grouped as B. This review should be consulted by those collating or interpreting data on these subjects.

Some of the large literature on this subject is cited in the references given, and it seems that the present situation is that the matter must be regarded as sub judice.

\section{7: Sex Proportions in Sibships}

There has been much interest in the question of whether the sex of one child has any influence on that of the next born sib and as to whether the distributions of the sexes in each sibship size show heterogeneity between families. One approach has been to look for any undue proportion of single sex sibships. The data necessary for examination of these patterns are not available from national statistics but several bodies of data have been published from recordings compiled for diverse purposes.

A variety of statistical techniques has been applied to the extensive data collected by Geissler (1889), Schützenberger (1949), Renkonen (1956), Edwards and Fraccaro (1958) and others. It has usually been found that the observed distribution of male and female births differs from the expectations derived if the sex of each birth is attributed purely to chance, but the basis of this deviation is not clear. Edwards (1958) came to the conclusion that ' $p$ ', the probability of a birth being male, varies significantly between families. Such an assumption of two or more subgroups within a population with different frequencies of male births leads to an expectation of a slightly higher number of single sex sibships, which fits the available data fairly well.

Schützenberger (1949) preferred to attribute the variation to a significant positive correlation between the sexes of successive births. Renkonen (1956) quoted by Edwards (1961) also found an association between the sexes of successive births, and this conclusion was confirmed in an independent analysis of the same data by Edwards (1961).

On the other hand, Edwards and Fraccaro (1960) analysing just under 24,000 births representing the completed families of 5477 Swedish ministers of religion, were 'unable to find any evidence that determination of sex is not a chance effect'. All of these analyses utilize the sex proportion of all births in the data studied as an estimate of the probability ' $p$ ', that a given child will be male; ' $p$ ' being always slightly greater than 0.5 . Hewitt, Webb, and Stewart (1955) from data collected in series of 3909 and $\mathbf{7 1 4 2}$ families in different areas in course of an investigation into the health of newborn infants found a significant excess of all male sibships over expectation.

Although such studies cannot be expected to provide any information on the important question of why this excess of male births over female births should exist, they do provide a fascinating glimpse of complex factors which may be operative in determining the secondary sex ratio in man. Despite the care that has been taken, heterogeneity of data and the small magnitude of the observed effects make it difficult, at this stage, to draw any general biological conclusions other than that ill-understood factors do probably exist, which influence the sexes of successive children within individual families.

A quite different problem is posed by the remarkable families encountered from time to time where over many generations male or female members only have offspring of their own sex. Two such pedigrees are reproduced by Stern (1960).

\section{8: Effects of Parental Age and Birth Order}

Inevitably ages of spouses are correlated and in turn the ages of spouses when children are born are correlated with birth order. The usual 'birth order' used is of children born alive but some authors use a 'mature birth order', i.e. counting live and stillbirths and some a 'pregnancy order' which includes all pregnancies which last long enough to be recognized.

Ciocco (1938) using data from the United States from 1915-1934 concluded that the sex ratio of live births fell with advancing parental ages but was 
unable adequately to separate the effects of maternal age, paternal age, and live birth order. Lejeune and Turpin (1957) analysed the same and later United States birth registration statistics and they also were unable to separate maternal and paternal age effects satisfactorily, but concluded that these, rather than parity, were the important variables.

Novitski (1953) concluded that the sex ratio was not directly associated with maternal age, but showed an inverse relationship to paternal age, sex proportions being lower in the offspring of older fathers. Novitski and Sandler (1956) calculated multiple linear regressions for data of the United States Bureau of Vital Statistics of the years 19471952 inclusive. They confirmed that the sex ratio of white live births in this population was significantly correlated with paternal and not with maternal age. In addition, however, their analysis indicated an association between sex ratio and birth order, the proportion of males being highest for first births and dropping rapidly between first and third births, after which it remained fairly constant.

This work was extended by Novitski and Kimball (1958) who obtained special tabulations of United States birth data for 1955 which gave sex, parental ages, and birth order for individual births. Quadratic regressions between the different variables were analysed, and the conclusions of Novitski and Sandler (1956) were substantiated and elaborated. It was found that, though for high paternal ages the association with sex proportion was more or less independent of birth order, for younger fathers this association fell very rapidly with increasing birth order. The authors also stress a highly significant term in their regressions relating to an interaction between paternal age and birth order, for which it is not easy to suggest a biological interpretation. They go on to point out that they ... place no great reliance on birth order or paternal age as having a direct influence on secondary sex ratio but feel rather that these two items represent easily characterised attributes of any given birth for which large amounts of data are available and that they are in all probability themselves correlated with other factors, more closely related to the true causes of the variations in sex ratio'.

The association of any shifts in sex ratio with paternal age cannot be attributed to any influence of the father's X chromosome on male mortality, but no adequate explanation can be advanced. Novitski and Kimball (1958) suggest that these phenomena are to be explained in pre-zygotic terms, which would either be a smaller proportion of Y-bearing spermatozoa from older fathers or that $\mathrm{X}$-bearing sperm from older fathers are more effective fertilizers of ova.

\section{9: Other Factors Influencing Secondary Sex Ratios}

Stillbirth rates are higher in multiple than in single births, and the excess male mortality in multiple births is greater than in single births. Both effects are most marked in monozygous pairs, but are present also in dizygous pairs of twins (Barr and Stevenson, 1961). It is therefore important in considering or comparing data to note whether all births or only single births are considered. In comparing different populations it should be remembered that though the frequency of monozygous twinning does not appear to vary significantly in different populations dizygous twin frequencies may vary by a factor as high as four in different countries (Stevenson, Johnston, Stewart, and Golding, 1966).

Many other factors have been shown or suspected to be associated with deviant sex ratios. These include illegitimacy, parental intellectual levels and occupations and ages of parents when the first child was born. Interpretation of these phenomena is, in our present state of knowledge, extremely diffcult.

\section{2: RELATIONSHIPS OVER TIME BETWEEN STILLBIRTH RATES AND SEX RATIOS OF LIVE AND OF STILL- BIRTHS}

In spite of the large number of papers on sex ratios of mature births no consideration appears to have been devoted to search for any changes in live and stillbirth sex ratios associated with fluctuations in stillbirth rates. Ciocco (1938) could find no relation between stillbirth rates and live birth sex ratios, but he did not consider stillbirth sex ratios; and further, over the years which he studied, there was no marked fluctuation or trend in the stillbirth rates in the United States.

Since 1928 stillbirths have been registrable in England and Wales, so that the sex proportion of foetuses in utero at the beginning of the 28th week of gestation, stillbirth rates in each sex, and the sex proportions of live, still-, and total births, can be calculated from figures published by the Registrar General. The stillbirth rates for each sex and these sex proportions in respect of single legitimate births from 1936-1964 are plotted in Fig. 2.

It will be seen that the stillbirth rates in both sexes have fallen very considerably over the period but that the levels in males have fallen relatively more sharply than those in females. At the beginning of 
the period male stillbirth rates were higher than in females by over 4 per 1000 total births, but over the past six years the rates have been very close together, and in three of these years the female has exceeded the male rate.

Over this period the sex proportions of stillbirths have fallen and though there have been year-to-year fluctuations, the sharpness in the fall is such that its technical significance is not in doubt. Live and total birth sex proportions have varied relatively little and appear, as expected, to have approached each other over the period. As live births contribute between 96 and $98 \%$ of total births during the period, the sex proportion of the latter will be dominated by that of the former. If the sex proportion of total births had remained more or less constant, then variation in live birth sex proportions would be expected to be determined entirely by variation in stillbirth sex proportions. However, only a very small rise in live birth sex proportions would be anticipated over the period, as they so greatly outnumber stillbirths.

These phenomena are all suggested by the data, but it is difficult to demonstrate them formally. It would permit many simplifications of calculations if it could be shown that the total birth sex proportion, i.e. the sex proportion of foetuses in utero at 28 weeks, did not vary. However, it does not seem possible to demonstrate this with confidence. Indeed it seems unlikely that a biological variable of this type does not change. It must depend on a constancy of the primary sex proportion and probably also of rates of pre-28th week losses. It is reasonable to suppose that in the latter any fluctuation in frequencies of environmentally determined losses would cause some changes in relative frequencies of losses by sex, as is demonstrable in the post-28th week losses.

As some $15 \%$ of pregnancies which are recognized probably end in abortion, much smaller changes in sex proportions than those observed in stillbirths would be expected to have detectable effects on the sex proportions of foetuses surviving to 28 weeks.

Whatever the real situation the evidence advanced suggests relatively little variation in the sex proportion of foetuses alive in utero at 28 weeks. This is the justification for making the assumption that live birth sex ratios are constant in a number of calculations later in this review. The assumption is implicit, though not mentioned, in all the total mutation rate estimates made by other authors which are considered later. It is only on this assumption that the behaviour of mutation rates in the sexes over periods of years may be compared.
Reconciliation of the more marked fall in male than in female stillbirth rates with a number of hypotheses is discussed in Section 3.5 below.

Trend analysis of these data needs more sophisticated treatment than is appropriate to this review. It is intended to consider the problems more formally in a future paper based not only on data from England and Wales but on those of other countries.

\section{3: EARLY MORTALITY BY SEX IN UTERO}

It has long been known that the male excess of stillbirths is usually even greater than in live births and that stillbirth rates are usually also greater in males. Typical papers were those of Tschuprow (1915), Schultz (1918), Parkes (1926), Ciocco (1938), and Strandskov and Bisaccia (1949). These and other papers suggested that the younger the foetus the higher the sex ratio, and extrapolation of the plots, some of which were almost linear, back to conception suggested an extremely high primary sex ratio. However, as Wilson (1926) pointed out, owing to the prominence of the clitoris in younger female embryos, accurate macroscopic sexing on the appearance of the genitalia becomes progressively less reliable as the age of the foetus decreases. Mistakes start to occur in sexing in foetuses under 20 weeks of age and under 12 weeks naked eye sexing is unreliable. Even histological sexing of gonads, which is a very large undertaking if sufficient numbers are to be studied, only enables the sex of foetuses to be determined as far back as about 7 weeks of post-ovulation age or about 9 weeks of post-menstrual age. However, the advent of nuclear sexing (Moore and Barr, 1954), the demonstration that embryos could be sexed by this method (Glenister, 1956), and the evidence that nuclear sex of young embryos corresponded to that of cells in chorionic villi (Stevenson and McClarin, 1957) made possible the sexing of large amounts of abortion material. The findings from such investigations have been reviewed by Stevenson $(1962,1966)$.

A number of fallacies may arise, however, from sex chromatin studies of aborted material. XO karyotypes, known to occur with relatively high frequencies in spontaneous abortions, would be nuclear sexed as 'male'. There are considerable doubts as to whether, even though cells look viable and stain well, the sex chromatin body is always identifiable in amnion or chorion which has been free from attachment to the uterus for some time before discharge. Nevertheless, individual specimens from missed abortions which apparently have lain free in the uterus for several weeks may have chorionic 
villi with cells which are easily sexable. It seems that on the whole biases of the above types would result in an excess of concepti being classed as males.

\section{1: Sex Chromatin Findings in Therapeutic Abortions}

In four series where material from therapeutic abortions was examined Serr and Ismajovich (1963) found a sex ratio of 1.66 in 125 abortions, Csordás, Dömötöri, Gergely, and Rechnitz (1963) a sex ratio of 1.27 in 1083 abortions induced before 12 weeks, and Schultze (1961) a ratio of 2.32 in a series of 223 such abortions covering a range of duration of pregnancy up to 17 weeks. Szontagh, Jakobovits, and Mehes (1961) found a sex ratio of 1.22 in 309 medical abortions. If it is assumed that such therapeutic abortions yield a random sample of the intrauterine population by sex, such figures point strongly to the presence of more males than females in utero between 8 and 20 weeks' duration of pregnancy. Although technical problems could have determined some overestimation of 'males', it seems improbable that there is not a real over-all male excess.

\section{2: Sex Chromatin Findings in Spontaneous Abortions}

There is more information concerning spontaneous abortions which have been sexed by the nuclear sex method. If the sex proportions from these series are plotted by age from 4 to 24 weeks postfertilization, they all show the same type of curve, though there are considerable variations in the mean sex ratios and in the highest points of the curves in different series (Stevenson, 1966). Characteristically going backwards from six months the male to female ratio rises to a peak somewhere between 12 and 18 weeks and then falls, approaching or even falling below unity in the earliest abortions sexed.

The only study where information is available by sex about all pregnancies terminating in a defined community over a given period of time is that reported by Stevenson and Warnock (1959). In this series all abortions were identified and the frequency was about 12 per 1000 total pregnancies. Material from about one-third of them was recovered and nuclear sexed (Stevenson, 1959). Assuming that those sexed were a representative sample (they were demonstrated to be representative in so far as duration of pregnancy and pregnancy order were concerned), it is possible to estimate with some confidence the sex proportion in utero from the earliest periods at which abortions were recognized to late stillbirths and live births. Mortalities over the whole period in utero from 4-40 weeks in males and females were, respectively, 155 per 1000 male and 128 per 1000 female concepti. At the beginning of the period there were estimated to have been in utero $\mathbf{4 8 7 6}$ male and $\mathbf{4 4 9 5}$ female embryos, a sex proportion of 0.520 . The corresponding sex proportion for live births was 0.512 , so that there was an absolute as well as a relative excess of male losses in utero.

With data of this kind, estimated mortality in each sex by 4 -week periods in pregnancies lasting 4 weeks to term can be plotted and this is done in Fig. 1. In the pregnancy periods of 28 weeks and over, the data have been calculated on the basis that living survivors appear in the denominators even if they were born prematurely, i.e. the mortality is that which occurred in utero in each period in all foetuses present in utero at the beginning of the 28 th week less those stillborn before the period started.

It will be noted from Fig. 1 that there is a slight excess of females lost in the earliest period and that the period where most concepti were lost was around 10 weeks. It is of interest also that in Stevenson's data there wa: a small excess of females in post-28th week stillbirths, though (as calculated from the numbers who must have been in utero at 28 weeks) there were more males 'at risk'.

\section{3: Chromosomal Sex of Abortions}

Several hundred spontaneously aborted concepti and about the same number of concepti from the therapeutic abortions have had adequate chromosomal analyses (World Health Organization, 1966). In both series where the karyotype was euploid there was a small excess of XX's over XY's. However, the numbers were small and were the pooled data from many studies. The findings of individual authors vary considerably.

In these spontaneous abortions the excess of females appears to be mainly in those lost early. Much more data will be needed before the real position is known; the finding of an excess of females in the spontaneous abortions does, however, indicate the need for care in interpretation of the data from nuclear sexing.

If the therapeutic abortions represented a random sample of the population of concepti in utero from about the 5th-27th post-menstrual week, then the excess of females found in that population is impossible to reconcile with the vast amount of data available, which indicates clearly that at the beginning of the 28th week there is constantly an excess of males in utero. If at 10-11 weeks, when about half of all abortions had already occurred, the sex 


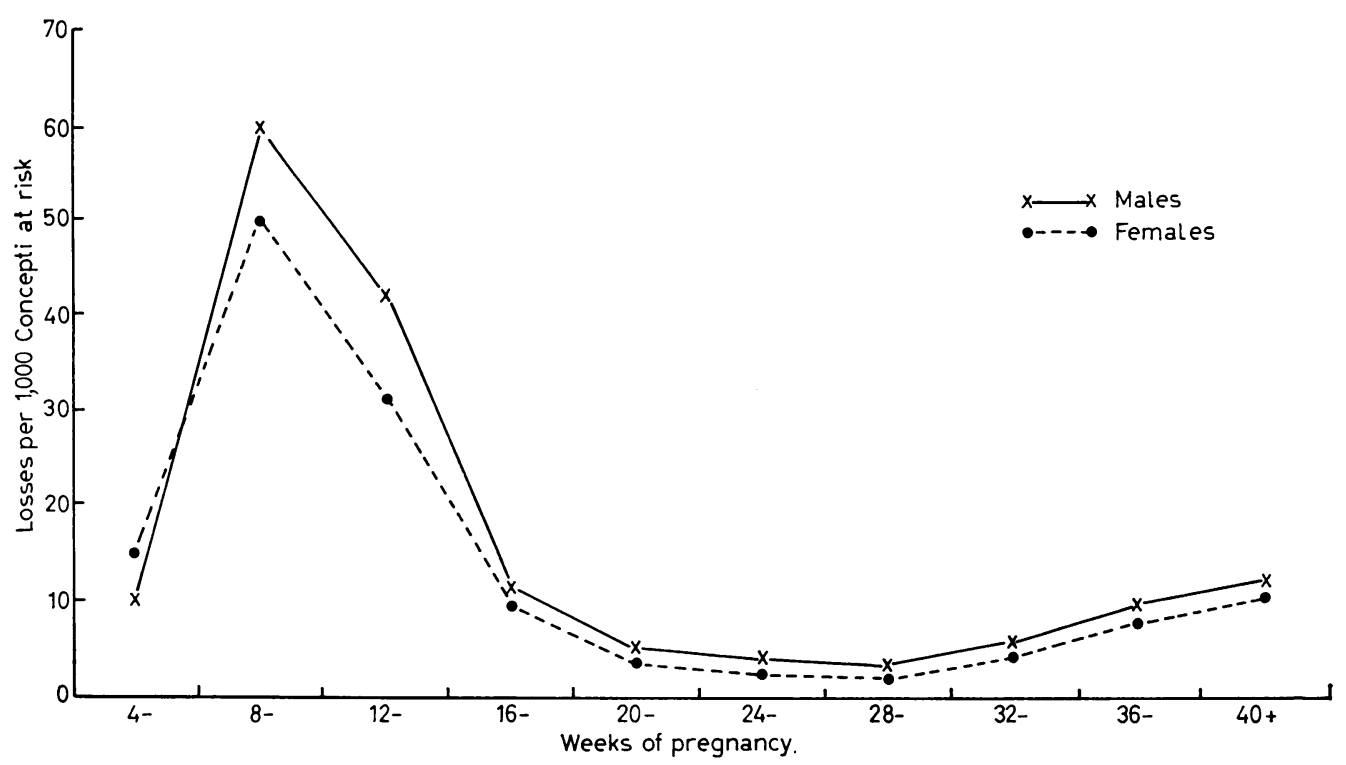

FIG. 1. Losses by abortion or stillbirth in each sex per 1000 concepti at risk in pregnancy weeks 4-40. [Based on data of Stevenson (1959).]

proportion of the remaining foetuses in utero was even 0.5 , then to reconcile with a sex ratio of 0.515 at 28 weeks the $7 \%$ of the concepti lost between the 11 th and 27th weeks would have to consist of twice as many females as males.

Until there are larger series of chromosomal examinations of aborted material, the discordance between nuclear sexing and chromosomal sexing findings has to remain somewhat of a mystery. However when allowance is made for the fact that, in the ratios quoted above (from chromosomal sexing of spontaneous abortions) XO's are ignored, and that these constituted as many as about $5 \%$ of those with $\mathrm{XX}$ and $\mathrm{XY}$ karyotypes (Section 5 below), the differences between findings based on nuclear sexing and those based on chromosomal sex are substantially reduced.

It seems that, ignoring complications of sex chromosome aneuploidies, it is justifiable to assume (1) that as at $\mathbf{2 8}$ weeks there is constantly an excess of males in utero, and as preceding recognizable mortality has been predominantly male the mean sex proportion of concepti in utero between 6 and 28 weeks is probably over $0.5 ;(2)$ that of spontaneous abortions more than half are males; (3) that there is much to suggest that in the earliest spontaneous abortions the numbers of males and females lost are either very similar or that there is a female excess; (4) that at present we can have little confidence in estimates of the sizes of these variables.

\section{4: Primary and Subsequent Sex Ratios}

There is as yet no information from human data as to the numbers and sex ratios of concepti lost in the earliest stages of pregnancy, before abortions become clinically recognizable. If, as in the mouse, such pre-implantation losses account for a considerable proportion of zygotes, and if in man these losses tend to affect one sex more than the other, they may lead to a considerable difference between the true primary sex ratio at conception and the earliest observed sex ratios in abortion material.

As already noted, it is almost certain that there are more males than females in utero at the time that identification of the sex of concepti is possible. It has often been deduced that the primary sex ratio is likely to be well above unity. If, however, the excess loss of females in early abortions mentioned in Section 3.2 above is a real phenomenon, and if this relative loss of females is of sufficient magnitude, the numbers of male and female zygotes may indeed be equal.

In short, we are not in a position on the basis of present evidence to estimate a primary sex ratio in man, and it cannot be stated with any certainty that it is above or below unity, or that it is not exactly unity, as would be expected on the simplest of Mendelian hypotheses. For further speculation on this point Stevenson (1966) may be consulted. 


\section{5: Changes in Intrauterine Mortality}

There can be little doubt that improving socioeconomic conditions and standards of medical care in all countries are consistently followed by reduction in post-28th week mortality. In respect of abortions, however, there is no information at all available on secular changes in frequencies. This is particularly unfortunate in the context of explaining sex proportions of surviving foetuses. As $15 \%$ or so of all concepti recognized are aborted, and in these there is a preponderance of males, any marked change in abortion frequency would almost certainly affect the sex proportion in utero at 28 weeks and stillbirth and live birth sex proportions.

Information on the frequency of abortion is unsatisfactory. Data from health departments in areas where abortions are registrable are known to be unreliable, and there have been many controversies as to the proportion of abortions which are illegal, i.e. criminally induced in different populations. Goodhart (1964) has reviewed briefly this controversy. Hospital data are of little value as seldom, if ever, are all women who are aborting admitted to hospital, and it is therefore difficult to relate such data to a 'population of pregnancies'. Most gynaecological textbooks are vague on the subject, reflecting clinical impressions or rather unsystematic questioning of women at various stages of completion of reproductive life as to outcomes of previous pregnancies. Most published information comes from this approach and the range of frequency estimates is usually from $12-15 \%$.

The data from Belfast (Stevenson and Warnock, 1959) are probably reliable for that city, as strenuous attempts were made to identify each pregnancy in residents terminating over a given period of time. Even then the figure of $12 \%$ was probably an underestimate. Warburton and Fraser (1964) by questioning women in Montreal derived a figure of $14 \cdot 7 \%$.

The scanty information available from many sources suggests that there is little variation in frequencies of abortion in different populations, relative to that encountered in stillbirths, the maximum and minimum probably not varying by more than a factor of 1.5 . In contrast those for stillbirths are known to vary by as much as a factor of 7 .

It has to be remembered that about $25 \%$ of spontaneous abortions are determined by detectable chromosomal aberrations (World Health Organization, 1966)(Section 5 below), most being aneuploidies or polyploidies. We do not have any information, except regarding maternal age, of any factors that would cause this proportion to vary. Further the proportion of abortions where the foetus is grossly abnormal is over $50 \%$ (Malpas, 1938; Stevenson, Dudgeon, and McClure, 1959). Not all those malformed have chromosomal abnormalities or vice versa. Further, we know that the over-all frequencies of all malformations in stillborn and live born infants do not vary much in different parts of the world (Stevenson et al., 1966). It seems, therefore, that we can account for well over half of the abortions in terms of causes already present in the zygote or determined early in embryogenesis.

\section{4: INTERPRETATION OF EXCESS MALE MORTALITY IN UTERO IN GENETIC AND ENVIRONMENTAL TERMS}

By analogy with drosophila it might be expected that X-linked lethals and detrimentals acting in utero would contribute to the excess of male over female prenatal mortality, which has been so frequently observed. If this is so, and if the magnitude of the effect could be estimated, then the way would be open to estimating the total mutation rate on the $\mathrm{X}$ chromosome along the lines followed by Muller with drosophila.

There can be little doubt that more males than females are lost as abortions, and in most sets of data used by those who have made calculations involving $\mathrm{X}$-linked mutations more males than females die as stillbirths, though, as noted in Section 2, recent United Kingdom data suggest that stillbirth rates in the two sexes are now approximately equal.

It does not seem logical, however, to stop at birth, if an a priori assumption has been made that some proportion of excess male mortality in late stages in utero is due to $\mathrm{X}$-linked recessive mutations. Throughout infancy, childhood, and adult life male exceeds female mortality.

\section{1: Shifts in Sex Ratios of Stillbirths with Falling Stillbirth Rates}

Although no information is available concerning abortions, the reduction in stillbirth rates, which is characterized by a greater fall in male than in female rates as noted in Section 2, immediately suggests three points. The first is that the over-all reduction is difficult to explain other than in terms of improving medical care and socio-economic conditions, even if the factors concerned cannot be precisely identified. The second is that these improved environmental conditions appear to have benefited males more than females, indicating that the sexes differ in susceptibility to some environmental influences. The third is that, for this reason as well as for others, it is fallacious to think of differences 
between stillbirth rates in the sexes as a reasonable measure of detriment due to $\mathrm{X}$-linked recessive mutations, unless it can be established that environmental effects have been excluded. Estimates based on such a procedure would lead to values of mutation rates which differed very greatly depending on whether, for example, the United Kingdom figures of 1936-1940 or those of 1958-1964 were used. Indeed there is no significant difference between the rates in the sexes in the latter period, so that on this reasoning there would be no contribution from X-linked lethals.

\section{2: Expectations on Various Models Postulating Genetic and Environmental Explanations of Falling Stillbirth Rates}

Such reduction over time of stillbirth rates, and any relative changes in mortality by sex which have occurred over the period, should throw light on the relative importance of the environmental and genetical contributions to male mortality. A selection of models may be examined; all are of necessity oversimplified, but they are instructive. One simplification, which is not incompatible with evidence previously advanced, is that the proportion of males and females in utero at 28 weeks remains constant.

The same terminology will be used in each model. $M_{t}$ and $F_{t}$ are the numbers of males and females in utero at 28 weeks. $\quad M_{d}$ and $F_{d}$ are the numbers of male and female stillbirths, $M_{1}$ and $F_{1}$ are the numbers of male and female live births. Therefore $\frac{M_{t}}{F_{t}}, \frac{M_{d}}{F_{d}}$, and $\frac{M_{1}}{F_{1}}$ are, respectively, the sex ratios of all foetuses in utero at 28 weeks, stillbirths, and live births; $\frac{M_{d}}{M_{t}}$ and $\frac{F_{d}}{F_{t}}$ are male and female stillbirth rates. On the assumption in the preceding paragraph, $\frac{M_{t}}{F_{t}}$ may be regarded as constant. Finally, $M_{t}=M_{d}+M_{1}, F_{t}=F_{d}+F_{1}$, etc.

Model A. It is assumed that all stillbirths are due to environmental influences, and that with improving socio-economic circumstances and medical care, the rates are diminished in each sex by the same proportion ' $p$ ' of the previous probability of death of a foetus which had survived to 28 weeks. This probability is the same as the stillbirth rate.

The initial stillbirth rates were $\frac{M_{d}}{M_{t}}$ and $\frac{F_{d}}{F_{t}}$. Following reduction of each stillbirth rate by a factor ' $p$ ', the new stillbirth rates will be $\frac{M_{d}}{M_{t}}-p\left(\frac{M_{d}}{M_{t}}\right)=\frac{M_{d}}{M_{t}}(1-p)$ and $\frac{F_{d}}{F_{t}}-p\left(\frac{F_{d}}{F_{t}}\right)=\frac{F_{d}}{F_{t}}(1-p)$. The relative values of $\frac{M_{d}}{M_{t}}$ and $\frac{F_{d}}{F_{t}}$ have not changed, nor has the sex ratio of stillbirths altered if the ratio $\frac{M_{t}}{F_{t}}$ is constant.

The original sex ratio of live births was $\frac{M_{1}}{F_{1}}$. After improvement $p\left(M_{d}\right)$ and $p\left(F_{d}\right)$ will survive to be born alive. Following reduction of the stillbirth rates the live birth sex ratio will therefore be $\frac{\left(M_{1}+p M_{d}\right)}{\left(F_{1}+p F_{d}\right)}$. If $\frac{M_{d}}{F_{d}}$ was originally greater than $\frac{M_{1}}{F_{1}}$, the new live birth sex ratio will be raised.

On such a model therefore the relative stillbirth rates in the sexes would remain unchanged. Over time, the plots of the two rates would not approach each other in the manner evident in Fig. 2.

Model B. Suppose that all stillbirths were due to environmental influences, except for a proportion $G$ of all male foetuses in utero at 28 weeks, which die before birth due to fully recessive $\mathrm{X}$-linked lethals. Male stillbirth rates would have two components, a proportion $\frac{G M_{d}}{M_{t}}$ due to X-linked lethals and (1-G) $\left(\frac{M_{d}}{M_{t}}\right)$ due to environmental causes.

Suppose that with improving environment, the rates are diminished in females by a fraction ' $p$ ', while in males only that part of the rate due to environmental factors $(1-G)\left(\frac{M_{d}}{M_{t}}\right)$ was reduced by the fraction ' $p$ '. The remainder, $\frac{G M_{d}}{M_{t}}$, would not be affected by environment. The new stillbirth rates in males would be

$$
\begin{gathered}
\mathrm{G}\left(\frac{\mathbf{M}_{\mathrm{d}}}{\mathbf{M}_{\mathrm{t}}}\right)+(1-\mathrm{G})\left(\frac{\mathbf{M}_{\mathrm{d}}}{\mathbf{M}_{\mathrm{t}}}\right)-\mathrm{p}(1-\mathrm{G})\left(\frac{\mathbf{M}_{\mathrm{d}}}{\mathbf{M}_{\mathrm{t}}}\right) \\
=(1-\mathrm{p})\left(\frac{\mathbf{M}_{\mathrm{d}}}{\mathbf{M}_{\mathrm{t}}}\right)+\mathrm{pG}\left(\frac{\mathbf{M}_{\mathrm{d}}}{\mathbf{M}_{\mathrm{t}}}\right)
\end{gathered}
$$

As in Model A, the new stillbirth rate in females would be $(1-p)\left(\frac{F_{d}}{F_{t}}\right)$. So the ratio of mortalities in the sexes, which is $\frac{M_{d}(1-p)+p G\left(M_{d}\right)}{F_{d}(1-p)} \times \frac{F_{t}}{M_{t}}$, will always be greater than $\frac{M_{d}}{F_{d}} \times \frac{F_{t}}{M_{t}}$.

Over time, therefore, we should expect the male stillbirth rate to fall less steeply than the female stillbirth rate and to flatten out as environment improves. $\mathrm{G}\left(\frac{\mathrm{M}_{\mathrm{d}}}{\mathrm{M}_{\mathrm{t}}}\right)$ will come to constitute an increasing proportion of male stillbirths, leaving fewer to be affected by improving environment. Again, this is not compatible with Fig. 2 in which stillbirth rates in the sexes approximate rather than deviate. The live birth sex ratio would rise on the above model, but to a lesser extent than in Model A.

Model C. If there were autosomal mutations acting individually or harmful constellations of genes which 


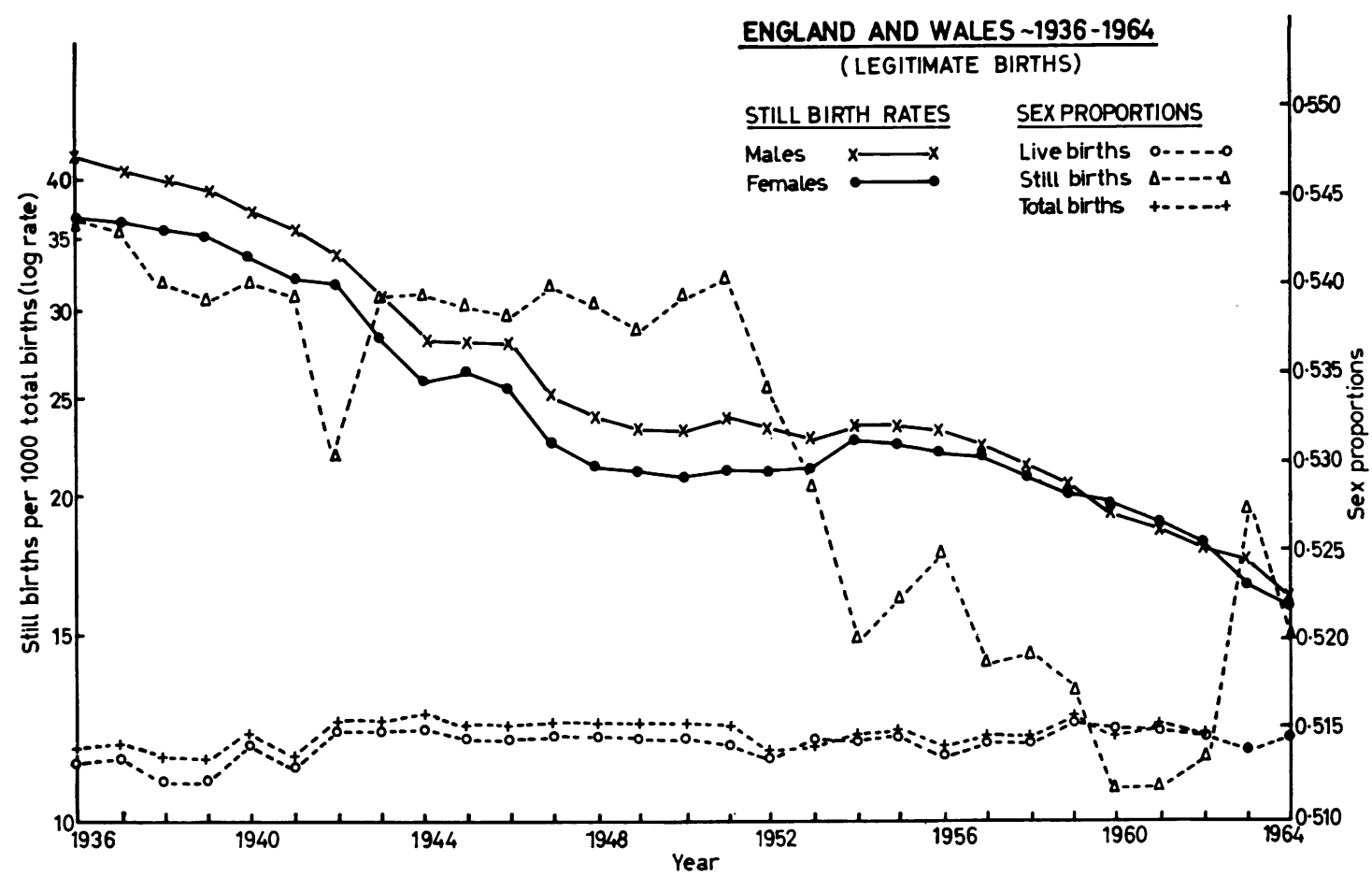

FIG. 2. Stillbirth rates by sex and sex proportions of live, still, and total births in England and Wales 1936-1964.

determined death in utero after 28 weeks, they would be expected to affect the two sexes equally (though sex limitation of some gene expressions cannot be excluded). Over time, therefore, with improving environment, the effects would be the same as in Model A.

Model D. Suppose that all stillbirths were due to environmental influences but that males were more susceptible, so that environmental improvement resulted in a greater reduction of stillbirth rates in males than in females. If $\frac{M_{d}}{M_{t}}$ is reduced by a fraction $p \frac{M_{d}}{M_{t}}$, and $\frac{F_{d}}{F_{t}}$ by a fraction $q \frac{F_{d}}{F_{t}}$, and $p>q$, then after improvement the rates would be $\frac{M_{d}}{M_{t}}(1-p)$ and $\frac{F_{d}}{F_{t}}(1-q)$. Over time, with progressive improvement, the death rates would fall more sharply in males than in females and the plotted rates would be expected to be similar to those in Fig. 2. The same holds for a combination of Models C and D.

It is unrealistic, however, to think that genotypic contributions to mortality remain constant in different environments. The forces of 'nature' and 'nurture' are seldom independent of each other.

In such unsophisticated models it is not easy to allow for detrimental mutations which do not confer the same probability of death in different environmental conditions. That there is a reduction of the harmfulness of some X-linked mutations as environment improves seems a reasonable supposition, and the expected effect would be a greater improvement in death rates in males than in females, i.e. essentially similar to Model D.

However, we cannot determine the extent to which an observed greater reduction in male than in female stillbirth rates such as that under discussion reflects such a situation, as by late foetal life males and females have diverged in their physiology and morphology and would not be expected to react in identical fashion to the same stimuli.

\section{3: Causes of Stillbirths in Male and Female Foetuses}

Although the causes of individual stillbirths are often obscure, it is possible to place them in broad aetiological categories and to compare the proportions by sex in these categories. The most informative study is that of McKeown and Lowe (1951) of 7066 single stillbirths.

Stillbirths were assigned to four classes, due to (a) disease or accident to the mother, (b) foetal malformations, (c) difficult labour, and (d) ill-defined or 
unknown causes. The sex proportion of each class could be related to the duration of gestation. Fig. 3 is reproduced by permission from the paper of McKeown and Lowe (1951). Sex proportions of all stillbirths increased from 0.498 at the 7 th month to 0.571 at the 9 th month and over. This change in sex proportion is in the same direction as that found by other authors, e.g. Strandskov and Bisaccia (1949).

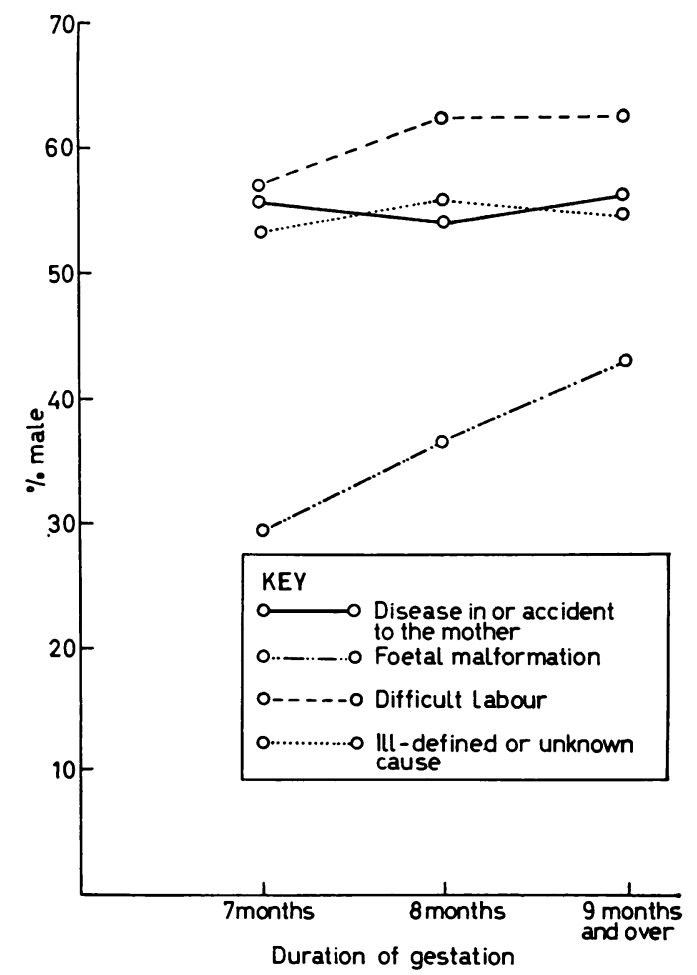

Frg. 3. Sex ratio of stillbirths related to cause and duration of gestation, Birmingham, 1936-1949. [By permission of T. McKeown and C. R. Lowe (1951).]

The authors explain the rise in terms of changes in relative frequency and sex proportions of the four classes at different durations of pregnancy, and particularly an increase of the sex proportion with duration of gestation in the class 'foetal malformations' which was due mainly to anencephalus and spina bifida. They also note that for every class of cause of death the sex proportions were higher for macerated than for non-macerated foetuses, a phenomenon which they attribute to male foetuses being retained in utero for longer after death.

\section{4: Discussion and Interpretation of Findings}

If the observations noted in Section 2 are at all representative of what happens when stillbirth rates fall, there being associated environmental improvements, then, as discussed above, any contribution to the male mortality from X-linked lethals or detrimentals must be very small. The phenomenon of the stillbirth rates in the sexes approximating as they fall is most readily explicable in terms of males being relatively more susceptible to noxious environmental influences than females. It seems impossible to estimate how much of this could be the result of X-linked detrimentals being less harmful under the improved conditions. It has to be remembered that males have a much higher mortality in the first year of life than females, and that the same phenomenon of the relative mortality rates in the sexes becoming closer over time can also be observed. It can hardly be doubted that reduction in infant mortality is associated with improved socio-economic circumstances and medical care.

The concept of greater susceptibility to environmental influences in males independent of genetic influences on the $\mathrm{X}$ chromosome seems to present difficulties to some. However, by the time that gonadal differentiation in embryogenesis is complete and the hormonal balances appropriate to males and females are established, the two sexes have different metabolic and growth patterns. These differences could be regarded as independent of genotypic influences except in so far as there was a genotypic contribution to the original dichotomy.

In drosophila, recessive lethals and detrimentals, whether autosomal or X-linked, act in egg and larval stages. Mutations that are lethal in the wider genetic sense, but act in the imago stage, also have visible manifestations. It is difficult to relate developmental stages in insects and mammals, but most autosomal recessive lethals in mice also kill early, shortly after implantation. There are also 'lethals' in the general genetic sense, which kill homozygotes shortly after birth, but these mostly have visible manifestations. There is little or no evidence of recessive lethals determining deaths in mice at periods corresponding to abortions or stillbirths in man. X-linked recessive lethals have probably not been demonstrated unequivocally in mice, but they would, like autosomal recessive lethals, be expected mainly to act in the early postimplantation stages.

By analogy with other species, therefore, we might expect $\mathrm{X}$-linked recessive lethals in man mainly to act early in pregnancy. It seems likely that, to some extent, wishful thinking has led to an assumption that part at least of the excess of males who are stillborn could be so interpreted. 


\section{5: DISCORDANCES OF PHENOTYPE, SEX CHROMATIN, AND SEX CHROMOSOME FINDINGS}

In previous sections it has, by implication, been assumed that all concepti may be classed as either 'male' or 'female' with corresponding XX or XY sex chromosome constitution. However, it is now well known that sex chromosome aneuploidies are remarkably common in man, and their presence must introduce some systematic error into sex ratios determined by any method other than actual chromosomal analysis. The nature and extent of this inaccuracy will depend on (a) the frequencies of the various aneuploidies, (b) the rate at which they are eliminated during intrauterine life, and (c) the methods used for determination of sex. Certain terminological problems also arise. For example, an XO foetus is neither 'male' nor 'female', and a term such as 'primary sex ratio' cannot be taken as an indication of the relative proportions of $\mathrm{X}$ - and Y-bearing sperm which fertilize ova, as it makes no provision for a third class of sperm which contains no sex chromosomes at all, or for a sperm which contains both $\mathrm{X}$ and $\mathrm{Y}$ chromosomes.

One approach to judging the amount of disturbance of sex ratios due to aneuploidy is to attempt to estimate what would have been the relative numbers of $\mathrm{XX}$ and $\mathrm{XY}$ embryos and foetuses if the different types of aneuploidies for which frequency estimates are available had not occurred. Our knowledge of the frequencies in the live born of the more common types is reasonably good, while information on frequencies in spontaneous abortions is steadily accumulating.

However, there are still three huge areas of ignorance, which will not be remedied quickly. (1) We know nothing of the numbers and types of sex chromosome aneuploidies eliminated in the first month of pregnancy, except perhaps that we can deduce that all or at least most YO zygotes are lost very early. (2) We know little of the relative frequencies of the many possible origins of these aneuploidies (first or second meiotic divisions, at syngamy or in cleavage divisions). Twiesselmann, Defrise-Gussenhoven, and Leguebe (1962) consider the theoretical problems that arise from the presumption that some meiotic accidents result in equal numbers of gametes monosomic and disomic for sex chromosomes. (3) It seems likely, on the evidence of $\mathrm{Xg}$ blood group inheritance, that when sex chromosomes are lost leading to XO concepti, in some $75 \%$ of cases it is the paternal sex chromosome which is missing (Race, 1965). In XO mice also, the chromosome missing is usually that from the father, and in that organism the commonest error may be failure of incorporation of a sex chromosome at syngamy (Russell and Saylors, 1963). Further, even when we know with certainty that a paternal sex chromosome is missing, we cannot tell whether it was an $\mathrm{X}$ or a $\mathrm{Y}$.

In view of these uncertainties, it is proposed here only to point to the consequences of the high frequency of XO karyotypes in concepti recognized in man, and to indicate their importance in determining sex proportions at different stages as identified by different methods. Of all zygotes with sex chromosome aneuploidies, probably well over $90 \%$ are $\mathrm{XO}, \mathrm{XXX}, \mathrm{XXY}$, or $\mathrm{XYY}$; and $\mathrm{XO}$ has a frequency several times that of the other three combined. From the data of Carr (1966) and smaller series by other authors (World Health Organization, 1966), it seems likely that some $5 \%$ of aborted concepti and $0.03 \%$ of the live born are of XO karyotypes, so that (assuming that $15 \%$ of recognized pregnancies end in abortion) about 0.008 of all concepti recognized are XO. It will be noted that, as the live birth frequency of XO's is about 0.0003 , only about 1 in 25 of the XO's which are present in utero at about the sixth week of gestation survive to live birth.

Spontaneously aborted XO's examined for nuclear sex will be chromatin negative and classed as 'males'. Those sexed on phenotype as later foetuses or live births will be classed as 'females'. If it is assumed that the above frequencies are approximately correct and the XO's are ignored, then some rough calculations can be made. If in a 'population of recognized pregnancies' the sex proportion of all concepti (based on nuclear and phenotypic sex, as appropriate) was 0.519 , that of abortions 0.570 , and that of post-28th week births 0.510 ; then by subtracting from the male abortions $5 \%$ of all abortions the sex proportion of abortions would be reduced to 0.547 and the sex proportion of all concepti to 0.515 . The effects of ignoring 0.0003 of post-28th week phenotypic females would be relatively small. Slightly more sophisticated approaches would be to assume that all XO's 'would have been' XX's or all $X Y$ 's; or that some 'would have been' $X X$ 's and some XY's. As noted above we lack the information necessary to justify such an exercise.

Twiesselmann et al. (1962) use as a starting point the frequencies of sex chromosome trisomies in mature births. However, present uncertainties as to the probabilities of survival in utero of embryos of such karyotypes and of the proportions of aneuploidies which arise in the two stages of meiosis, at syngamy and in cleavage divisions, make it doubtful if calculations so based have a practical value. 


\section{6: EVIDENCE FROM EXPERIMENTAL ANIMALS OF MECHANISMS INFLU- ENCING SEX PROPORTIONS}

\section{1: Sex-linked Lethals in Drosophila}

Most research work on sex-linked lethals in drosophila has been done in $D$. melanogaster. Probably about one X chromosome in 600 carries a recessive mutation which arose spontaneously in germ cells in the immediately preceding generation and which is lethal in homozygous females and hemizygous males (Muller, 1954). Much of the study of both spontaneous and induced mutations concerns those arising in male germ cells. The techniques mainly make use of absence of crossingover in the male and matings with females from a stock with $\mathrm{X}$ chromosomes which have an inversion (so preventing crossing-over) and which are also tagged by dominant visible gene markers. The origin of the $\mathrm{X}$ chromosome in the offspring of both sexes can be identified by the marker gene expressions. Proportions of living males with and without the marker chromosomes indicate rates of loss caused by spontaneously arising or induced lethals, and females heterozygous for lethal mutations may be recognized and so used for further breeding tests. Readily understandable accounts of the techniques used are given by Auerbach (1962).

It is generally accepted that these 'recessive' lethals have some dominance and so reduce fitness in the heterozygous female carriers. It appears to be agreed also that most of these recessive lethals arising spontaneously are true gene or point mutations and that only a few small deficiencies simulate their effects-a matter that can be established by cytological examination of the salivary gland polytene chromosomes of drosophila. The majority of $\mathrm{X}$-linked recessive lethals induced by, ionizing radiations are also gene or point mutations, though a higher proportion of such induced mutations, particularly if the radiation dose is large and rapidly delivered, are small deficiencies. However, most deficiencies are dominant in their effects. Indeed, dominant X-linked lethals, whether spontaneous or induced, are mostly deficiencies rather than point mutations and they can be demonstrated cytologically; they occur at much lower frequencies than gene mutations.

Regarding the frequencies of mutations on $\mathrm{X}$ chromosomes in the two sexes in drosophila, Muller (1945) estimates that in males the frequency of spontaneously arising lethals per $\mathrm{X}$ chromosome is about 2 per $1000 \mathrm{X}$ chromosomes in young flies (first week after hatching) but only about 0.6 per 1000 thereafter. His estimate of the over-all rate which he regards as conservative is about 1.3 per 1000 gametes. In females the comparable spontaneous frequency is about 1.7 per 1000 per $\mathrm{X}$ chromosome throughout life. There is thus no evidence of a higher spontaneous rate on $\mathrm{X}$ chromosomes in males than in females. It will be noted that the higher rate of mutations in young males is the reverse of the situation postulated in certain speculations about man (e.g. Krehbiel, 1966). In the past it has usually been considered that the relative frequencies of detrimental and lethal genes on the $\mathrm{X}$ chromosome of drosophila are about 3-5 : 1 (Timofeeff-Ressovsky, 1935; Kerkis, 1935; Muller, 1954), and that this ratio is similar for both induced and spontaneous mutation. Detrimentals reducing viability by less than about $10 \%$ would not be recognized individually, and there was evidence that they greatly outnumbered semi-lethals (defined as reducing viability by at least $90 \%$ ).

However, more recent work by Kafer (1952) and Friedman (1964) suggests a rather different picture. The latter author classes as lethals those mutations permitting up to $10 \%$ survival, and on that definition he estimated from his findings that the ratio of detrimentals to lethals was only 0.125 ; so that a very high proportion of all mutations were lethals as defined (or lethal or semi-lethal in previously used terminology). Further, as shown by previous authors, distribution of mutations by severity of effect was bimodal, most of the mutations being either near lethals or only having just demonstrable detrimental effects. Friedman suggests that in the earlier work the nutritional and general environmental situation of the cultures was less favourable than those now available, and that this change, and in irradiation work, the testing of earlier male germ cell stages, determined a higher proportion of detrimentals detected by previous workers. As pointed out by Neel (1957), the greatest uncertainty as to the number of mutations in drosphila that contribute to losses of eggs and larvae is determined by lack of information on the frequencies of very small effect mutations.

It has been observed repeatedly that in proportion to the relative amounts of genetic material, recessive lethals are detected less frequently on the X chromosome than on autosomes, and that this is so whether induced or spontaneously arising mutations are being searched for (Muller, 1950). This is believed to be accounted for, in part at least, by selection against male pre-meiotic cells which receive certain lethals on the $\mathrm{X}$ chromosome (Shapiro, 1936; Auerbach, 1954; Abrahamson, Meyer, Himoe, and Daniel, 1966). It is suggested by the last named authors that about half of all recessive 
lethals on the $\mathrm{X}$ chromosome determine spermatogonial death and so are not transmitted in gametes.

\section{2: Estimates of a Total Mutation Rate in Drosophila}

Muller (1950) calculates a total spontaneous mutation rate over the genome in drosophila by two methods, and in one of these the starting point is the total mutation rate to completely lethal genes on the $\mathrm{X}$ chromosome. It is in this classical paper that Muller develops his concept, based on principles advanced by Haldane and Fisher, of 'genetic death'. For practical purposes all mutations are considered to be harmful, even in hetrozygotes, and are ultimately eliminated from populations by selection, mainly against heterozygotes. Each mutation thus determines a 'genetic death'.

On such a basis the total number of genetic deaths over future generations can be derived from the total mutation rate. This original and ingenious reasoning gives a starting point for expressing 'total damage' due to gene mutations and in turn the additional damage which would be expected if mutation rates were raised by exposure to ionizing radiation or other mutagenic influences.

As this type of reasoning has been applied to man, it is worth while noting the steps in Muller's argument leading to his estimate of ' $\mu \mathrm{T}$ ' the sum of the rates of gene mutation of all kinds over the genome. Muller (1954) accepts the evidence of Timofeeff-Ressovsky (1935) and his own work that complete or almost complete lethals occur 7-8 times as frequently as visibles, and that detrimental mutations occur some 3-5 times as frequently as lethals. The relative frequencies of detrimentals: lethals: visibles are therefore about 18:7:1. These are recessive mutations, and detriments assigned to them are those appropriate to homozygotes or hemizygotes. The detriment determined in heterozygotes is not necessarily in proportion to their severity in homozygotes (Muller, 1954).

Muller (1950) on the evidence of his own work and that of his colleagues considers that lethals on the $\mathrm{X}$ chromosome only arise with one-sixth of the frequency of those on chromosomes II and III combined. Allowing for there being only one $\mathrm{X}$ chromosome in males, he concludes that as the combined frequency of detrimentals and lethals on the $\mathrm{X}$ chromosome is about six times that of lethals alone, the total mutation rate over the genome is about 34.5 times that of lethals on the $\mathrm{X}$ chromosome. Taking 1.5 per 1000 as the combined mutation rate to lethals on the $\mathrm{X}$ chromosome, the calculated mutation rate over the genome is 51.75 per 1000 , or about $5 \%$ per gamete per generation.
If this is divided by an estimate of the mean spontaneous rate per locus of $10^{-5}$, the estimated number of loci at which mutations occur is $\mathbf{5 0 0 0 \text { . }}$

This brief and superficial consideration of some facets of mutation on the X chromosome in drosophila and conclusions which may be drawn from them may appear to be diversional, but as will be seen there is little or no evidence from experimental mammals or from man on the subject of harmful mutations on the $\mathrm{X}$ chromosome, and findings in drosophila have dominated speculation as to the situation in man.

\section{3: Other Genetic Mechanisms Influencing Secondary Sex Proportions in Drosophila}

It has to be remembered that the role of the chromosomes in sex determination in drosophila is different from that in man. Thus, though the normal sex chromosome complement in the sexes is the same as in man, in drosophila XO individuals are males and XXY individuals are females. In addition, the presence of extra autosomes, in triploidy, tends to determine maleness of the individual. Thus, distortion of secondary sex ratios by certain chromosome anomalies would differ in drosophila and mammals.

In most inbred strains of drosophila the secondary sex proportion is less than 0.5 , i.e. there is an excess of females. However, the extent of the excess is characteristic of the inbred strain and appears to be determined predominantly by the male parent. Thus, Hanks (1965) reports experiments where in strains of D. melanogaster, Oregon- $R$ and Canton$S$, mating the males from the two stocks with a third strain of females resulted in female proportions of progeny of 0.535 from Oregon-R males and 0.513 from Canton-S males. Reciprocal crosses between the two strains showed female proportion of 0.536 from male Oregon-R $\times$ female Canton-S crosses and 0.514 from male Canton-S $\times$ female Oregon-R crosses.

Such findings are incompatible with a postulate of the characteristic sex ratios being due to differing numbers of X-linked mutations in the stocks, and it seems intrinsically unlikely that the effect was due to differing numbers of Y-linked detrimentals in the strains. It cannot be completely excluded that these findings are in some way determined by differential zygotic mortality by sex, but Hanks regards this as improbable and considers that they are much more likely to be due to prezygotic phenomena.

Hanks (1965) records further evidence pointing in the same direction from mating single Oregon- $R$ males with single $X$ and attached $X(X X Y)$ females. 
Some males were mated first to single $\mathrm{X}$ females and some first to attached $\mathrm{X}$ females to obviate any age effects. It was found that the crosses with single $\mathrm{X}$ females gave a female proportion in progeny of 0.541 , while with attached $\mathrm{X}$ females the female proportion was 0.396 . In these matings there was a significant correlation between the proportion of females in free $X$ matings and that of males in attached $\mathrm{X}$ matings, as would be expected if the reason for the preponderance of females in normal $\mathrm{XY} / \mathrm{XX}$ matings was a relative deficiency of fertilizations by $\mathrm{Y}$-bearing sperms and the failure to survive of $\mathrm{XXX}$ and $\mathrm{YY}$ zygotes.

In a subsequent report Hanks (1966) describes a parallel phenomenon in D. melanogaster. Extensive tests of males of two strains show marked differences in the sex proportions of progeny. Analysis of data suggested that this phenomenon was associated with a recessive gene or genes on chromosome III. These findings in no way cast doubt on the evidence for the occurrence of spontaneously arising and induced X-linked recessive lethals in drosophila determining losses of male zygotes. They do point, however, to the importance of other genetic mechanisms which act in prezygotic cell stages.

Novitski and Sandler (1957) produce evidence from $D$. melanogaster that in offspring of matings of males carrying a translocation between the $\mathrm{X}$ chromosome and the small 4th chromosome to attached $\mathrm{X}$ females, the four expected types of offspring do not occur in equal proportions. Such disturbances of segregation associated with chromosomal anomalies have long been known, but it has usually been assumed either that some of the male gametes are lost in meiotic divisions or that the resulting gamete determines a non-viable zygote. However, in the experiments reported, egg counts strongly suggested that too many adults were recovered from a given number of eggs for lethality in eggs to be the explanation. The authors considered it improbable that there was differential fertilization by gametes of differing chromosome constitution on the grounds that grossly unbalanced gametes usually fertilize successfully, and that the lowest frequency gametes observed were those with the least chromosome disturbances. They favour the view that there is preferential segregation of chromosomes into 'functional' and 'non-functional' gametes.

Another phenomenon also called 'sex ratio' was first described by Gershenson (1928) in D. obscura. It has subsequently been studied in $D$. pseudoobscura, in which it was shown by Sturtevant and Dobzhansky (1936) to be due to an inversion on the $\mathrm{X}$ chromosome which determines that few or no sons, but almost twice the expected number of daughters, are produced.

\section{4: Other Known Influences on Sex} Proportions in Drosophila and Other Insects

Counce and Poulson (1962) discuss the maternally transmitted 'sex ratio' factor of Malogolowkin and Poulson (1957), and show that the agent is a treponema-like spirochaete infecting the ooplasm, which results in the death of most $\mathrm{XY}$ individuals during embryogenesis. A maternally transmitted factor causing a high male embryonic mortality and thus a female preponderance of up to $100 \%$ in the live offspring has also been observed in the scolytid beetles (Lanier and Oliver, 1966). Attempts to establish the presence of a spirochaete were unsuccessful, but there seems little doubt that this factor, whatever its nature, is transmitted in the cytoplasm. Other breeds of these insects produce a high proportion of female offspring by the mechanism of gynogenesis-a parthenogenetic process stimulated by the act of mating.

The differentiation of the sexes in culicini genera is apparently determined by segregation of a single gene pair. Hickey and Craig (1966) discuss certain lines in which the production of a high proportion of male offspring is determined by the paternal genotype. The authors ascribe this phenomenon to a 'distorter' locus, causing abnormal segregation of the chromosome bearing the sex-determining locus in male gametogenesis. Affected males produce fewer functional sperm than normal. This mechanism is obviously similar to the phenomenon of 'meiotic drive' which has been postulated in drosophila (e.g. Peacock and Erickson, 1965).

These few examples are intended only to illustrate the range of problems that are involved in sex proportions in some animal species.

\section{5: Sex Proportions in Mice and Other Mammals}

In drosophila most of the precision in identification of sex-linked lethals comes from the technique of using marker chromosomes and the prevention of crossing-over between $\mathrm{X}$ chromosomes at meiosis in female germ cells. Available techniques in the mouse are of necessity much less precise, in that dominant markers on the $\mathrm{X}$ chromosome in the mouse are few in number, no inhibiting inversion on the $\mathrm{X}$ chromosome is available to prevent crossing-over in females, and the $\mathrm{X}$ chromosome forms only about $6 \%$ of the total chromosome length of the haploid genome compared to about $33 \%$ in drosophila. 
In most strains of mice rather over $50 \%$ of the live born are males, but there is considerable variation, and certain well-established inbred strains have unusual sex proportions which show little variance. The same problems that arise in the interpretation of a male preponderance of live births in man are therefore present in mice. As in man, the basic question raised by the excess of male live births is whether this excess results from (a) a primary sex proportion of 0.5 followed by excess female losses; (b) a primary sex proportion of greater than 0.5 determined by prezygotic phenomena followed by equal losses by sex or a small excess loss of males; or (c) conceivably, but probably less likely, a primary sex proportion of less than 0.5 followed by a great excess loss of female zygotes?

Theoretically losses in utero could more readily be studied in the mouse than in man, as pregnant females can be sacrificed and foetuses can be sexed by naked eye or histological examination of gonads. However, the very large numbers of early foetuses which would have to be examined histologically to have any confidence in findings almost limit this approach to sexing by naked eye examination of genitalia and gonads as far back as this is possible.

In mice, on average about $10 \%$ of zygotes appear to be lost before or shortly after implantation, and it is not possible by any method to judge the potential sex of the very early losses. Even in later stages, after a placenta is formed sex chromatin could not, until recently, be demonstrated in mice, so that the earliest when sexing was possible has been when the gonads have developed sufficiently for histological differentiation. These difficulties have so far, as in man, prevented a direct estimate of the primary sex ratio. Recently, however, Bianchi and Bianchi (1966) have shown that nuclear sexing of very early amnion and chorion is technically feasible.

However, it is possible to determine how many ova have been shed by counting corpora lutea, and how many failures at implantation have occurred from the number of implantation 'moles'. These, taken in association with the numbers of living and dead foetuses, enable the fates of ova shed to be estimated.

In studies of sex proportion problems, therefore, drosophila, mouse, and man each presents some advantages. In man, very large numbers of live and stillbirths and post-6th week abortions can be studied, and screening of nuclear sex is not difficult, but virtually nothing is known of peri-implantation losses. In the mouse, numbers of corpora lutea, implantation losses, later embryonic and foetal losses, and live births can be studied, but only later intrauterine losses and the live births can be sexed. In drosophila, marker chromosome techniques can be used extensively and larger numbers can be screened than in mice, but the dead eggs cannot be sexed.

Lüning (1962) has considered evidence on intrauterine mortality by sex in mice from a number of different points of view. $\mathrm{He}$ is careful to point out that his work has been entirely on the CBA strain, and that in view of the known differences in sex proportions at birth in other lines and of specific factors (predominantly transmitted by males) which influence sex ratios in mice, no general conclusions should be drawn. Nevertheless, the findings are relevant to these problems of primary and subsequent sex proportions.

Lüning noted that in these mice there was an over-all sex proportion at birth of about 0.52 , but that the proportion of males decreased with increasing litter size. This phenomenon was the reverse of that found by Howard, McLaren, Michie, and Sandler (1955) and that demonstrated by Hammond (1934) in rats. Lüning pointed out that his data could be explained if it was assumed that female zygotes die more frequently than males, i.e. in smaller litters more females had been lost. When litter size was about 8 the sex proportion of live births was about 0.5 , and there was no constant relation between the number of fertilized eggs and the sex ratio at live birth.

Lüning argued that if there were no losses in utero the sex ratio at birth would represent the sex ratio of implanted zygotes. He, therefore, examined in separate uterine horns the sex of living foetuses and the few that had died (there being relatively few post-implantation losses in mice), and counted the implantation sites. His findings were that in horns where no losses had occurred the sex proportion of foetuses was very close to 0.5 , whereas in those horns where there had been losses of zygotes at implantation or shortly thereafter the sex proportion was on average about 0.52 . The difference was, however, not significant. There was no correlation between the total number of zygotes which had implanted and the sex proportion of living foetuses. He also added together the numbers of foetuses from horns where all concepti (dead or alive) had developed to a stage where sexing was possible and found again the sex proportion very close to $0 \cdot 5$.

He interprets these findings as being compatible with a hypothesis that the sex proportion of implanted zygotes in this strain was about 0.5 , and that the excess of males at live birth resulted from an excess of female losses in the immediate post- 
implantation stages. These findings are of interest when compared with those in man mentioned in Section 3, and they are not compatible with an explanation that many zygote deaths are determined by X-linked lethals. Both Lüning and Howard et al. (1955) conclude that females are more susceptible than males to environmental influences in utero and that many sex proportion fluctuations are explicable on this basis. However, their agreement of opinion on this matter in so far as it is derived from sex proportions by litter size appears to be based on contradictory data.

\section{6: Sex Proportions in Different Strains of Mice and Other Mammals-Maternal and Paternal Influences}

The findings of King (1918) had suggested that when inbred lines of rats were crossed the sex proportions of the progeny were mainly determined by the dam. However, Gates (1930), in a linkage experiment in mice in which 8 males sired 1437 offspring, found inconclusive but suggestive evidence that there were different sex proportions in the progeny of some males irrespective of the dam. Weir (1953) described two strains of mice, one with a high blood $p \mathrm{H}(p \mathrm{HH})$, which had a consistent sex proportion of about $55 \%$ in progeny, and another with a low blood $p \mathrm{H}(\mathrm{pHL})$, which as consistently had progeny with a sex proportion of about $45 \%$ males. In a subsequent paper Weir (1955) reported findings on the sex proportions of progeny of reciprocal crosses of these two strains. In each cross the characteristic sex proportion of the strain appeared in the offspring of males of that strain. The sex proportions did not appear to vary with litter size, which did not support a hypothesis that differential mortality by sex in utero was the explanation of the phenomena observed.

In a subsequent paper (Weir, 1962) these experiments were repeated. In addition, males of the $p H H$ and $p H L$ lines were mated with females of a third strain, and again the sex proportion of progeny was that characteristic of the strain to which the male belonged. Experiments using double matings and mice with marker coat colour genes pointed in the same direction.

That certain classes of sperm may contribute disproportionately to zygotes is suggested by segregation ratios from the $T$ locus complex in the mouse. Gruneberg (1952) gives a good summary of the basic genetics. Braden (1958) showed that if copulation takes place at ovulation there is a large excess of affected offspring over an expected Men- delian ratio of $1: 1$ when ' $t$ ' allele segregates in the male from ' $T$ ' or ' + ' and the dam is ' ++ '. However, if copulation is delayed for about 4 hours the excess of affected is greatly reduced. When the genotypes of the parents are reversed the expected $1: 1$ ratio is observed in the progeny. It appears therefore that spermatoza carrying ' $t$ ' are at a slight advantage in the early post-ovulation period relative to those carrying ' $T$ ' or ' + ', but that this advantage largely disappears later. Hart and Moody (1949) demonstrated in normal rats that the sex proportion rose by about $5 \%$ for every hour after ovulation by which copulation was delayed.

Cattanach (1962) studied the progeny of XO female mice with markers on the $\mathrm{X}$ chromosome. Assuming that YO offspring are lost in the periimplantation period, it would be expected that the remaining progeny would in equal numbers be $\mathrm{XX}$, $\mathrm{XO}$, and $\mathrm{XY}$. However, there was a marked deficiency of XO offspring, there being only 30-37\% as many as $\mathrm{XX}$ females. The mean litter size was 5.3 which did not suggest that most of the missing $\mathrm{XO}$ females died in utero, though very early losses of XO's might have facilitated a high survival rate in remaining embryos. The possibility is suggested of gametes lacking an $\mathrm{X}$ chromosome selectively segregating into polar bodies. In view of the findings in man where such a high proportion of XO's die in utero, the problem requires further investigation.

McWhirter (1956) has shown significant heterogeneity in the sex proportions of offspring derived from semen from 32 bulls. Moore and Price (1948) found a highly significant excess of females in the offspring of rats conceived after the animals had been for 60 days at an altitude of over 7500 feet. Bittner (1936) found changes in sex proportions of mice offspring following changes of diet; and Sawin and Gadbois (1947) demonstrated marked changes associated with systems of breeding and with diet in rabbits.

The work of Hahn and Hays (1963) suggests that the sex proportion in rats may be subject to hormonal influences. Daily injections of progesterone were given to the females for the first 8 days of pregnancy, at which stage about half of the group were ovariectomized. Daily administration of progesterone and oestrone was continued until the 20th day of gestation, at which stage the animals were sacrificed and the sex ratios of living foetuses ascertained. These data were compared with a third untreated group. The sex ratios were $101 \cdot 2$ for the controls, 80.4 for the ovariectomized, and 122.2 for the intact hormone-treated group. The differences between the groups are statistically 
significant. In the authors' opinion, the effect observed is unlikely to be due to sex reversals, particularly at the dosages employed, and therefore they suggest that the maternal hormonal environment can influence the differential survival by sex in utero of rat foetuses.

\section{- 6.7: Sex Proportions on Offspring of Irradiated Mice}

Parkes (1925) appears to have been one of the first to publish findings of the sex proportions of live born progeny of irradiated mice. He gave 'substerility' doses to males and mated them over periods from 0-57 days thereafter so that the sampling was probably of gametes irradiated in post-meiotic germ cell stages. (If it is desired to test for induction of mutations in spermatogonia, it is usual to allow an interval of 90 days before mating, so as to allow for elimination of all post-spermatogonial germ cell stages, e.g. Lüning and Sheridan, 1964). The numbers of progeny were small and only one of the differences was technically significant. There was an over-all reduction in sex proportion of progeny, but a rise was noted in litters sired 0-4 days after paternal irradiation. Hertwig (1938) could find no effects on sex proportions following $400 r$ to $1400 \mathrm{r}$ to gonads of males which were mated in presterile period. Charles (1950) deduced that there were probably 2 sex-linked lethals in 3072 offspring of male mice which had received $60 \mathrm{r}$, and 1 in 2755 controls. Kalmus, Metrakos, and Silverberg (1952) published data suggestive of a sharp increase in sex proportions at birth of progeny of male mice who had received 150-300 $\mathrm{r}$ to late germ cell stages. However, Trasler and Metrakos (1953) subsequently repeated the experiment with negative results.

Few of the early experiments involved irradiation of females, mainly because any substantial doses induced permanent sterility. Snell and Ames (1939) found in rather small numbers of progeny that as dosage increased, the litter size appeared to fall and the number of males per litter fell more rapidly than the number of females. However, later findings, with much larger numbers, do not appear to support such results.

In Lüning's (1962) experiments in which the CBA mothers came of a stock where the males had been irradiated for several generations, and where therefore some small accumulation of $\mathrm{X}$-linked lethals in females might have been expected, there was a small reduction in the proportion of live born males in small litters, which was compatible with elimination of males by X-linked mutations, but in larger litters there was an excess of males. Searle
(1964), in experiments on the viability of offspring of females whose fathers had been irradiated, found a significant reduction in sex proportion, but subsequent tests could not demonstrate that the effect was due to X-linked lethals. Recently Grahn, Verley, and Leslie (1966) described a technique using an $\mathrm{X}$-linked lethal marker to ensure that XO females did not disturb sex proportions observed in the offspring of irradiated males. Preliminary results are interpreted as suggesting that a $500 \mathrm{r}$ gonadal dose to the spermatogonial stage in fathers determines induction of a lethal on $1 \%$ of their $\mathrm{X}$ chromosomes. (If, as suggested by the work of Abrahamson et al. (1966) in drosophila, any significant proportion of mutations induced had been spermatogonial lethals in the mice, then the rate of induction was even greater.)

Chapman, Hansen, Havenstein, and Morton (1964) have given an interim report of a carefully designed experiment involving irradiation of male and female lines over a number of generations. This report covers the results of the first four generations of mice; none of the parameters studied had as yet diverged significantly from the controls, but data on the sex ratio of offspring of male mice (receiving $450 \mathrm{r}$ per generation) suggested an estimated mutation rate to sex-linked recessive lethals of $2.14 \pm 1.5 \times 10^{-4} / \mathrm{r}$. The authors predict that another five generations will be needed for the results to approach statistical significance. It, therefore, still remains to be seen whether this sophisticated approach, or that of Grahn et al. (1966), can continue to demonstrate significant shifts in sex ratio, and whether such shifts can be shown to result from $\mathrm{X}$-linked mutations.

As immense numbers of male and female mice have been irradiated in other experiments, particularly in Oak Ridge National Laboratory and other centres in the United States and in Harwell in this country, it might have been expected that some findings of the effects of parental irradiation on live birth sex ratios would now be available. Although in more instances than might have been expected the data are unsuitable for such analyses (for example, in many experiments the progeny were only sexed at weaning), there are very large amounts of data available. Little of this information is published in a form suitable for independent analyses, however, and there have been no major publications since the review of Russell (1954).

Russell has reviewed and supplied to the United Nations Scientific Committee on the Effects of Atomic Radiation large amounts of data from Oak Ridge, and Carter and Searle have supplied similar information from Harwell to UNSCEAR and to the 
Medical Research Council Committee on the Hazards of Nuclear and Allied Radiations. Unfortunately, no data have ever been published, and it appears still to be assumed that it must be possible to draw some conclusions from mouse data. However, the real position is probably that this is not correct and that no further conclusions can be drawn than those discussed by Russell (1954). Kohn (1960) reviews his own and the Russell data, and concludes that there is no convincing evidence of an increase in sex proportion in the offspring of irradiated fathers, exposed at any germ cell stage.

Auerbach, Falconer, and Isaacson (1962) have recently undertaken experiments using dominant visible marker genes in mice designed to identify lethals induced by radiation over a segment of the $\mathrm{X}$ chromosome between the loci marked by $\mathrm{Bn}+$ (Bent tail) and $\mathrm{Mo}^{\mathrm{br}}$ (Brindle). Males hemizygous for tabby $(\mathrm{Ta}+)$ were irradiated and then mated to females having an $\mathrm{X}$ chromosome marked by $\mathrm{Bn}+$ and $\mathrm{Mo}^{\mathrm{br}}$. Any induced lethals between $\mathrm{Bn}$ and $\mathrm{Mo}^{\text {br }}$ loci would be indicated by absence of tabby males in the progeny of F1 females. The presence of one such son was taken to indicate that the F1 female did not carry such a lethal.

Seventy-nine tabby males were irradiated with doses of $600 \mathrm{r}$ and $500 \mathrm{r}$. They were mated immediately after exposure and up to a maximum of 22 days thereafter, so that post-meiotic germ cell stages were tested for induced lethals. Of these males, 61 produced 154 daughters suitable for complete testing. As Bent tail males have reduced viability, segregation ratio tests could not be used, but repeated testing revealed no lethal mutations induced in this segment in $\mathbf{1 5 4}$ females tested. One sex-linked visible (recessive anaemia) appeared in an F2 male. On the basis of previously published cross-over frequency data between $\mathrm{Bn}$ and $\mathrm{Mor}^{\mathrm{br}}$ it was postulated that the distance between the two loci would include about 100 loci at which mutations to lethals might occur. Assuming that the rate of lethals induced per $r$ was about $75 \%$ of the rate of induction of recessive visibles at the seven specific loci so much used in mutation experiments, the expected frequency per $500 \mathrm{r}$ was estimated at about 0.018. Carter (1959) estimated from his experiments that one autosomal recessive lethal was induced in spermatogonia on average by $600 \mathrm{r}$ to $800 \mathrm{r}$; or by $300 \mathrm{r}$ for later germ cell stages. Auerbach et al. (1962) estimate that the same rate of induction on the $\mathrm{X}$ chromosome would have resulted in $500 \mathrm{r}$ inducing 0.017 mutations on the segment of the $\mathrm{X}$ chromosome which they tested. They note that the finding of no mutations in 154 chromosomes tested in their experiments was not significantly different from these predictions which were based on other types of experiment.

Since Carter's work, improved methods of testing for induction of recessive lethals have been used by Lüning (1964) and Lyon, Phillips, and Searle (1964). Both authors tested induction in spermatogonia of recessive lethal equivalents which act around implantation. Such mutations are probably more similar in type to $\mathrm{X}$-linked recessive lethals than the lethal alleles at the seven specific loci. The number of mutations detected following a rapidly delivered radiation dose was 10 times as high as that found by Carter. This suggests that the negative findings of Auerbach et al. (1962) on a section of the $\mathrm{X}$ chromosome represent a significantly lower rate of induction or manifestation of recessive lethals. Whether this is to be explained in whole or in part in terms of spermatogonial lethals on the $\mathrm{X}$ chromosome in the mouse can only at present be a matter of speculation.

\section{8: Conclusions From Experimental Animals as to Mechanisms Affecting Secondary Sex Ratios}

It appears that there are many influences on the live birth sex ratio in all species investigated. The existence of recessive lethal or detrimental mutations on the $\mathrm{X}$ chromosome of mammals acting in utero has still not been conclusively demonstrated, and the assumption that such mutations do occur in man must therefore still be based on general genetical considerations, and on the unequivocal evidence from drosophila.

Other evidence points to prezygotic phenomena as being of importance in the determination of sex ratios, perhaps by influencing the proportions of different types of functional gametes produced. Environmental influences demonstrated include hormonal balance in mother, and an infective agent. The suggestive evidence that under some circumstances females are more susceptible than males to environmental influences in utero is of particular importance, and must be remembered when any indices are used which compare male and female mortalities.

\section{7: SEXES OF OFFSPRING OF HUMAN PARENTS WHOSE GERM CELLS HAD BEEN EXPOSED TO IONIZING RADIATION}

There are three main sets of data concerning the sex proportions of offspring of irradiated parents. Neel and Schull in a series of papers have reported on live born children of parents exposed to radiation from the nuclear explosions in Hiroshima and 
Nagasaki (Neel and Schull, 1956; Schull and Neel, 1958; Neel, 1963), and there are two major studies of the sex of offspring following therapeutic irradiation of parents before conception of the children; those from France (Turpin et al., 1956; Lejeune and Turpin, 1957; Lejeune, Turpin, and Rethore, 1960) and that from the Netherlands (Scholte and Sobels, 1964). In all these studies the gonadal doses received by parents had to be estimated retrospectively, and reservations as to their accuracy are expressed by all the authors. These data have been considered in UNSCEAR (United Nations, 1962) and in many other publications and no extensive critical analysis will be attempted in this review.

The Japanese data were assembled by identification of pregnancies and births when they were registered for food-rationing and other procedures. The radiation dosages received by parents were calculated from distances of the parents from the epicentres of the explosions. Persons not exposed to radiation in Hiroshima and Nagasaki and in the city of Kure were used as controls. The persons in the French series had been exposed to therapeutic irradiation above certain minimal levels of dosage to gonads. The data were assembled by postal questionnaire to which only about $33 \%$ of females and $37 \%$ of males replied. The 'control' sex ratios for comparison were derived from data on children born to the same parents before the radiotherapy. The parents who had had radiotherapy in the Netherlands were similarly identified from hospital records. In this series the children born to the patients before and after their treatment were traced from municipal birth registers. It was considered that all such children were identified.

In the French and Dutch series, the use as controls of the sex distributions of children born before irradiation of parents is complicated by the known correlations of sex proportions with parental age and birth order as discussed in 1.8 (Ciocco, 1938; Novitski, 1953).

\section{1: Offspring of Irradiated Mothers}

It is convenient to consider separately the data in respect of the offspring of irradiated mothers and of those of exposed fathers. Fully recessive lethals induced on maternal $\mathrm{X}$ chromosomes would be expected to reduce the proportion of males in the offspring of irradiated mothers, while such mutations induced on the $\mathrm{X}$ chromosome of males would only be passed to daughters and would not therefore influence the first generation offspring sex ratios.
Tables I and II include data, seriatim, from Schull and Neel (1958), Macht and Lawrence (1955), Lejeune et al. (1960), and Scholte and Sobels (1964). It is clear that the crude data from France and Holland are very similar. In both, the sex proportions taken as controls are those of children born to the parents before irradiation. In both they are very high in children born to mothers before

TABLE I

EFFECT OF IRRADIATION OF MOTHERS ON THE PROPORTION OF MALE OFFSPRING*

\begin{tabular}{|c|c|c|c|c|c|}
\hline \multirow[b]{2}{*}{ Country } & \multicolumn{2}{|c|}{ Control } & \multicolumn{3}{|c|}{ Irradiated } \\
\hline & $\begin{array}{l}\text { No. of } \\
\text { Live } \\
\text { Births }\end{array}$ & $\begin{array}{l}\text { Per- } \\
\text { centage } \\
\text { Male }\end{array}$ & $\begin{array}{l}\text { Dose } \\
\text { Range } \\
\text { (rads) }\end{array}$ & $\begin{array}{l}\text { No. of } \\
\text { Live } \\
\text { Births }\end{array}$ & $\begin{array}{c}\text { Per- } \\
\text { centage } \\
\text { Male }\end{array}$ \\
\hline $\begin{array}{l}\text { Japan } \\
\text { U.S.A. } \\
\text { France }\end{array}$ & $\begin{array}{c}\text { Control } n \\
355 \\
674\end{array}$ & $\begin{array}{l}\text { available } \\
54 \cdot 6 \\
50 \cdot 1\end{array}$ & $\begin{array}{r}\sim 8 \\
\sim 75 \\
\sim 200 \\
50-200 \\
200-400 \\
2-10\end{array}$ & $\begin{array}{r}19,610 \\
3958 \\
2268 \\
407 \\
161 \\
797\end{array}$ & $\begin{array}{l}51 \cdot 979 \\
51 \cdot 440 \\
51 \cdot 190 \\
49 \cdot 1 \\
44 \cdot 7 \\
52 \cdot 2\end{array}$ \\
\hline $\begin{array}{l}\text { Nether- } \\
\text { lands }\end{array}$ & 242 & $54 \cdot 1$ & $70-135$ & 230 & 48.5 \\
\hline
\end{tabular}

* Reproduced from Health Physics (1966), 12, 282, by permission of the Health Physics Society.

TABLE II

EFFECT OF IRRADIATION OF FATHERS ON THE PROPORTION OF MALE OFFSPRING*

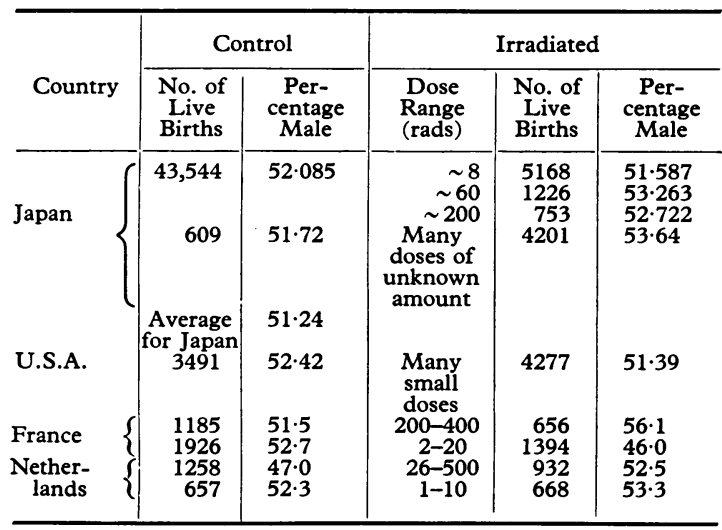

* Reproduced from Health Physics (1966), 12, 282, by permission of the Health Physics Society.

irradiation, particularly in the series of mothers who subsequently had large therapeutic doses. As noted in Section 7.2 below, the control sex proportions in the irradiated fathers' series are much lower, so that the magnitudes of shifts in sex proportions of progeny following irradiation of male or female parents are exaggerated. 
The Japanese data are much larger, and the control sex proportion used seems much more representative of live birth sex proportions in the whole population than those used in the therapeutic irradiation series. Further, the post-exposure sex proportions fall with increasing dose as would be expected if the radiation received by the mothers was determining the effect of reduction of sex proportions. However, none of the differences between controls and irradiated is technically significant.

The findings of Kaplan (1957) on the sex proportions of children subsequently born to mothers treated by ovarian irradiation for sterility point in the same direction. Of 407 such children, 200 $(49 \%)$ were male. In short, all these sets of data suggest an effect, in that they consistently point in the same direction, but none are statistically significant, and it is impossible to arrive at any realistic quantitative estimates of dose effect relationships.

\section{2: Offispring of Irradiated Fathers}

The same three sets of publications from Japan, France, and the Netherlands contain most of the data on whether there is any disturbance of the sex proportions in the offspring of fathers who have been irradiated. If there should be such an effect and the induction and transmission of the causal factors were on the $\mathrm{X}$ chromosome, then any changes observed would have to be attributed to excess losses in utero of heterozygous females. As will be seen from Table II these data are inconsistent but suggestive of a rise in sex proportions of progeny of irradiated fathers.

In drosophila, though a majority of induced mutations on the $\mathrm{X}$ chromosome of males determine reduced viability of heterozygous females, the degree of dominance seldom exceeds about $20 \%$ and on average is probably less than $4 \%$. Some authorities consider that completely dominant lethals are almost invariably small chromosome deficiencies (Sonnernlick, 1940; Fano, 1941; Catcheside 1948; Catcheside and Lea, 1945). A proportion of these deficiencies might represent single hit phenomena, and the expectation would be that they would increase linearly with rapidly delivered radiation doses as do point mutations.

What appears to emerge from all these data is that, where mothers have been irradiated, there is in all the studies a reduction in the sex proportion of live births. Even though in none of these cases are the sizes of the shifts technically significant, and in all of them biases could have arisen in collection of the data, the consistency in the direction of the shift is impressive.
In the case of the offspring of irradiated males there is, on the whole, a rise in the sex proportion of offspring but the shifts are variable and small and in no case technically significant. The reality of the observed shifts is less impressive than those in the opposite direction, which were observed in the offspring of irradiated mothers.

The extent to which these shifts, if real, are determined by $\mathrm{X}$-linked lethals and detrimentals can only be a matter of opinion, but in view of the many possible explanations and the nature of the data it does not seem defensible to draw quantitative inferences.

\section{8: SOME PROBLEMS INVOLVED IN ATTEMPTS TO IDENTIFY AND MEASURE THE CONTRIBUTION OF X-LINKED MUTATIONS TO MALE MORTALITY IN UTERO IN MAN}

It is reasonable to suppose that in man as in other organisms recurring gene mutations arise all over the genome, that they are harmful to a much greater extent in homozygotes than in heterozygotes, and that some of them invariably determine death in utero (lethals), while others confer harm which determines a probability of death less than one (semi-lethals or detrimentals). It is further reasonable to suppose that some of these mutations are on the $\mathrm{X}$ chromosome, and that their expression in hemizygous males is as severe in effect as that in homozygous females.

Such X-linked mutations, whether completely lethal or only detrimental in hemizygous males, have not yet been identified in mammals, and most of the information and the theory derive from drosophila experiments. $\mathrm{X}$-linked recessive mutations in drosophila, like autosomal recessives, affect predominantly the viability of eggs and larvae. In mammals used in experimental work (most information being available in respect of mice), autosomal recessive lethals usually act to determine death in the peri-implantation period and, though some reduction in viability in the perinatal period can be detected, the effect is very small relative to that at earlier stages. It is likely that $\mathrm{X}$-linked recessive lethals and detrimentals also mainly act at this period. Although the occurrence of such $\mathrm{X}$-linked mutations has not been demonstrated in the mouse, this is probably because, the X-chromosome being small (about one-fortieth of the haploid genome length), they are so few in number relative to the autosomal recessives.

In the absence of contrary evidence it might be expected that, in man also, most recessive deleterious mutations whether autosomal or X-linked act 
TABLE III

MUTATION EQUILIBRIUM-GENETICALLY LETHAL SEX-LINKED RECESSIVE GENES

\begin{tabular}{|c|c|c|c|c|c|c|}
\hline \multirow{3}{*}{ Generation } & \multicolumn{4}{|c|}{ Females } & \multirow{2}{*}{\multicolumn{2}{|c|}{$\begin{array}{c}\text { Males } \\
\text { (all from mother) }\end{array}$}} \\
\hline & \multicolumn{2}{|c|}{ Inherited From } & \multicolumn{2}{|c|}{ New Mutation From } & & \\
\hline & Father & Mother & Father & Mother & Inherited & New Mutations \\
\hline $\begin{array}{l}1 \\
2 \\
3 \\
4 \\
5\end{array}$ & $\begin{array}{l}0 \\
0 \\
0 \\
0 \\
0\end{array}$ & $\begin{array}{c}0 \\
0 \\
\frac{1}{2} \times(V+\mu) \\
0 \cdot 75 x(V+\mu) \\
0 \cdot 875 x(V+\mu)\end{array}$ & $\begin{array}{l}0 \\
x V \\
x V \\
x V \\
x V\end{array}$ & $\begin{array}{l}0 \\
\mathbf{x} \mu \\
\mathbf{x} \mu \\
\mathbf{x} \mu \\
\mathbf{x} \mu\end{array}$ & $\begin{array}{c}0 \\
0 \\
\frac{1}{2} \times(V+\mu) \\
0.75 \times(V+\mu) \\
0.875 \times(V+\mu)\end{array}$ & $\begin{array}{l}0 \\
\mathbf{x} \mu \\
\mathbf{x} \mu \\
\mathbf{x} \mu \\
\mathbf{x} \mu\end{array}$ \\
\hline $\begin{array}{l}\mathrm{n} \\
\mathrm{n}^{*}\end{array}$ & $\begin{array}{l}\mathbf{0} \\
0\end{array}$ & $\begin{array}{c}x(V+\mu) \\
x(0.5 V+\mu)\end{array}$ & $\begin{array}{c}x V \\
x 0.5 V\end{array}$ & $\begin{array}{l}\mathbf{x} \mu \\
\mathbf{x} \mu\end{array}$ & $\begin{array}{r}\mathbf{x}(V+\mu) \\
\mathbf{x}(0.5 V+\mu)\end{array}$ & $\begin{array}{l}\mathbf{x} \mu \\
\mathbf{x} \mu\end{array}$ \\
\hline
\end{tabular}

* Eqilibrium if $50 \%$ of $\mathrm{X}$-linked mutations were spermatogonial lethals in males.

$\mathrm{V}=$ Mutation per male gamete per generation. $\mu=$ Mutation per female gamete per generation. $2 \mathrm{x}=$ Population.

Mutations begin to arise in the germ cells of generation $I$ at rates $V$ on male $X$ chromosomes and $\mu$ on female $X$ chromosomes per

chromosome per generation. (1:1 Sex ratio assumed-zero fertility in males-normal fertility in carrier females and full penetrance)

in the peri-implantation period. By analogy with the mouse, it would be most surprising if a sufficient number of $\mathrm{X}$-linked mutations arose spontaneously for their effects to be detectable. It should be noted, as discussed in Section 3, that by the time human pregnancy can be recognized there is almost certainly already an excess of males in utero. If the primary sex ratio is anywhere near unity, then there must be a very great preponderance of female losses in the pre-implantation or implantation periods.

In one way or another all attempts to identify the effects of $\mathrm{X}$-linked mutations in man presume an excess male mortality, which is probably justified, and then proceed to attribute the whole or part of such excess to killing of hemizygous males by these mutations. Before discussing the methods used and the estimates made it seems advisable to clarify a number of theoretical points which recurrently arise.

\section{1: Proportions of Mutations Received by Males Which Have Arisen de novo on $X$ Chromosomes of Immediate and More Remote Ancestors}

Fully Lethal Mutations. X-linked mutations received by males must have arisen de novo either in their mother or in one of her forebears. If a mutation is completely recessive and lethal in hemizygous males and if the sex ratio at conception is approximately 1.0 , then at equilibrium the derivation of the mutations is as in Table III. If mutation rates in the sexes (per $\mathrm{X}$ chromosome per generation) are equal, then one-third of all the lethals received by males originate on their mother's X chromosome. (The gene frequency in males ' $q$ ', is identical with the mortality in males and an estimate of the mutation rate to lethals would therefore be $\frac{1}{3} \mathrm{q}$.)

Mutations Less than Invariably Lethal in Effects. Considering the situation where the mutant gene is not fully lethal, at equilibrium $\mu=\frac{1}{3}$ sq; where $\mu$ is the mutation rate per locus per generation and ' $s$ ' is the probability of death determined by the mutation (for fully lethal mutations $s=1$ ) (Haldane, 1935). In this situation $\mathrm{q}=\frac{3 \mu}{\mathrm{s}}$, and the proportion of all mutations received by males which arose de novo on the mother's $\mathrm{X}$ chromosome is $\frac{\mu}{\mathrm{q}}=\mu \times \frac{\mathrm{s}}{3 \mu}=\frac{\mathrm{s}}{3}$, so that less than onethird of the mutations received would have arisen on the mother's X chromosome.

Results if Mutation Rates in Sexes are Not Equal. If mutations arise with different frequencies ( $\mathrm{V}$ and $\mu$ ) on male and female $\mathrm{X}$ chromosomes, then

TABLE IV

PROPORTIONS OF ORIGINS OF LETHAL X-LINKED RECESSIVE MUTATIONS IN MALES FOR DIFFERENT VALUES OF MUTATION RATES ON X CHROMOSOMES IN MALES AND IN FEMALES

\begin{tabular}{c|c|c|c|c}
\hline $\begin{array}{c}\text { Ratio of Mutation } \\
\begin{array}{c}\text { Frequencies on Male (V) } \\
\text { to those on Female } \\
\text { X Chromosomes }(\mu)\end{array}\end{array}$ & $\begin{array}{c}\text { Arose de novo on } \\
\text { X Chromosome } \\
\text { Received from } \\
\text { Mother }\end{array}$ & $\begin{array}{c}\text { Arose de novo on } \\
\text { X Chromosome of } \\
\text { Maternal Grandmother }\end{array}$ & $\begin{array}{c}\text { Arose de novo on } \\
\text { X Chromosome of } \\
\text { Maternal Grandfather }\end{array}$ & $\begin{array}{c}\text { Arose de novo on } \\
\text { X Chromosome of } \\
\text { More Remote Ancestor }\end{array}$ \\
\hline $\mathrm{v}: \mu=1: 1$ & $2 / 6$ & $1 / 6$ & $1 / 6$ & $2 / 6$ \\
$\mathrm{v}: \mu=2: 1$ & $2 / 8$ & $1 / 8$ & $2 / 8$ & $3 / 8$ \\
$\mathrm{v}: \mu=3: 1$ & $2 / 10$ & $1 / 10$ & $3 / 10$ & $4 / 10$ \\
$\mathrm{v}: \mu=4: 1$ & $2 / 12$ & $1 / 12$ & $4 / 12$ & $5 / 12$ \\
$\mathrm{v}: \mu=1: 0$ & 0 & 0 & $1 / 2$ & $1 / 2$ \\
\hline
\end{tabular}


these relationships do not hold. The proportions of 'freshly arising' and 'inherited' mutations would be expected to be as in Table IV. In the extreme case where there is no mutation in females and all mutations are recessive and lethal, half of the mutations received by males in any generation must have originated on the maternal grandfather's X chromosome and half on those of other maternal ancestors.

Consequences if Mutations are Not Fully Recessive. If lethal mutations are not completely recessive and if the mutation rates in the sexes are the same, then more than one-third of mutations received by males will have arisen on the mother's X chromosome. Similarly, if all mutation is in males, the proportion of all mutations with some dominance received by male zygotes, which arise on the maternal grandfather's $\mathrm{X}$ chromosome, will be more than one-half.

Spermatogonial Lethals. If, as in drosophila, $50 \%$ of X-linked lethals occurring in males are spermatogonial lethals, then the same mutation rate on male and female $\mathrm{X}$ chromosomes would result in a different equilibrium. Females would receive $0.5 \mathrm{~V}+\mu$ mutations which had arisen in the parents and in addition $0.5 \mathrm{~V}+\mu$ mutations transmitted from her ancestors by their mother. Male zygotes would receive $0.5 \mathrm{~V}+\mu$ through their mother and $\mu$ which had arisen de novo on their mother's $\mathrm{X}$ chromosome. So that, if $\mathrm{V}=\mu$, then of all mutations which males received two-fifths would have arisen de novo on the mother's $\mathrm{X}$ chromosome and if the initial mutation rates were the same in the sexes, only one-tenth of the mutations received by males would have arisen de novo on their maternal grandfather's X chromosome. This is effectively the same as where the mutation rate in males is half that in females, which corresponds to the last line in Table III.

\section{2: Relative Mutation Rates in Sexes}

Haldane (1947) on the evidence of data of Andreassen (1943) on haemophilia, in which it was thought that female heterozygotes could be detected, suggested that the mutation rate in males was higher than in females. However, as subsequently demonstrated, the data were faulty and the calculations were, therefore, not valid. Subsequently, Haldane (1956) suggested that the phenomenon of higher mutation rates in males than in females was demonstrable in X-linked muscular dystrophy. However, Cheeseman, Kilpatrick, Stevenson, and Smith (1958) showed conclusively that Haldane's conclusions were invalid, as they were based on data that were grossly defective in respect of ascertainment of sporadic cases. In drosophila, as previously noted, mutation rates to X-linked lethals appear to be higher in younger than in older males (Muller, 1945).

In spite of this, it is often assumed that mutation rates in males must be higher. The reasoning is that if any proportion of mutations represent 'copy errors', as there are many more gonial cell divisions involved in the large and continuous production of male germ cells than in females, more copy errors should be transmitted in the gametes of older males.

The notion of copy errors determining mutations appears to come mainly from bacterial genetics where the frequency of mutation is much more closely related to number of cell divisions than to time. There is no doubt that the mean age of fathers of presumed mutant subjects with a few specific dominant traits is high, notably in achondroplasia (Stevenson, 1957). But these are a minority of dominant gene traits and other explanations could be advanced. Stevenson (1958) could find no increase in maternal grandpaternal age at times of birth of mothers of sporadic cases of X-linked muscular dystrophy, and this is also true of a larger series of cases recently analysed by one of our colleagues (H. A. Johnston, unpublished, 1966). However, unless very large numbers were available it would not be expected that a real influence could be detected, particularly as 'sporadic' cases are not all mutants.

In the sections immediately following, it will always be assumed that X-linked lethals and detrimentals are completely recessive, so not increasing the probability of death in heterozygous females. This seems justified on grounds of simplicity and because the effects on heterozygous females would only be expected to be a few per cent of those in hemizygous males. In each generation of zygotes there will only be about two heterozygous females for each hemizygous male. However, it should be borne in mind that any disadvantage conferred on heterozygous females further invalidates the assumption sometimes made that any excess of male over female mortality is due to X-linked genes.

\section{3: Mutation Rates, Gene Frequencies, and Selective Disadvantages Conferred by X-linked Mutations which Reduce Chances of Survival in Utero}

As noted in section 8.1 , at equilibrium $\mu=\frac{1}{3}$ sq, and 'sq' is the mortality in utero determined by such mutations. It follows (a) that all mutations having equal mutation rates will in an equilibrium generation determine the same mortality as sq is constant, (b) that the sum of the mortality determined by such mutations will vary directly as the sum of the mutation rates to such mutations irrespective of how many mutations there are, at how many loci they occur, and whatever the values of ' $s$ ' conferred by the contributing mutations. 
In all these calculations the questionable assumption has to be made that the observed mortality in any generation reflects equilibria gene frequencies. This assumption is particularly unlikely to be valid when the mutations concerned are detrimentals reducing the probability of survival in utero, as that probability is likely to be varied by epistatic interactions with other mutations, the rest of the genotype, and environmental influences.

The starting point for all quantitative estimates of rates of mutations to $\mathrm{X}$-linked genes of these types must be the observed intrauterine mortality over a specified period of gestation. The first step must be a decision as to what proportion of the male mortality was caused by $\mathrm{X}$-linked mutations.

Having decided on an estimate of the male mortality so caused, then at equilibrium, when $\mu=\frac{1}{3}$ sq, the mortality observed, 'sq', is equivalent to three times the sum of the mutation rates of all genes contributing to the mortality. It should be noted that the mortality caused by any mutant at equilibrium is a function of the mutation rate only, and is not related to the value of ' $s$ '. This total mutation rate is, therefore not a rate of mutation to 'lethals' as described by some authors, nor is it a rate of mutation to 'lethal equivalents' as suggested by others. The term 'lethal equivalents' was introduced by Muller (1950) and elaborated by Morton, Crow, and Muller (1956). One lethal equivalent is defined as constituted by any number of mutations, segregating in different individuals in a population, which in homozygotes would confer individual probabilities of death, which summate to $1 \cdot 0$. Thus, one invariably lethal mutation or three conferring individual probabilities of $0 \cdot 2,0.3$, and 0.5 would constitute one lethal equivalent. Such reasoning is not applicable to X-linked mutations where what is measured is the sum of the effects of their hemizygous expressions in a 'population' of males.

\section{4: Estimates of Effects of Spontaneous Mutation on X Chromosome}

As already noted, the underlying supposition in attempts to identify the effects of harmful X-linked mutations acting in utero in man is that they cause male deaths additional to those determined by autosomal mutations and environmental influences. The problem is to find appropriate methods of identifying independently the $\mathrm{X}$-linked contribution. It cannot even be assumed that the three groups of determinants of deaths in males act independently of each other. For example, it could well be that part at least of the greater reduction of stillbirth rates in males than in females, which has occurred in the United Kingdom, and probably elsewhere, over the last half century, is due to the fact that the same X-linked mutations have conferred decreasing probabilities of death in males as social, medical, and economic circumstances have improved.

Two approaches to identification of an X-linked mutational contribution have been employed. The first uses as a starting point the higher mortality of males than of females in utero. If harmful environment determined an equal probability of death in the two sexes and autosomal mutations were equally distributed and affected the two sexes to the same degree, then the excess male mortality could, by a process of exclusion, be assumed to represent the effects of X-linked mutations. In fact, as pointed out in Section 4.1, judging by the information from variations of stillbirth rates in the sexes over time and the findings of McKeown and Lowe (1951) already discussed, it seems likely that the relative probabilities of death in the sexes, at each stage of gestation, vary according to the degree to which the environment is unfavourable.

The second approach is to correlate male mortality in utero with some variable which would be expected to influence the number of mutations which male concepti would be receiving. These reduce in practice to: (a) correlating male mortality with maternal age on the assumption that mutations accumulate with age, and that no other factors contribute to any correlation with maternal age; (b) correlating male mortality in utero with the age of the maternal grandfather when the mother was born; as any mutations which he accumulates with age will first be manifest in his daughter's sons. This, which is often called the 'three generation approach', was developed by Cavalli-Sforza (1961).

From the regressions calculated either in (a) or (b) it is possible to derive indirect estimates of 'mutation rates' by equating numbers of additional deaths associated with a unit rise in age of the mother or the maternal grandfather with a number of mutations which arose on their $\mathrm{X}$ chromosome.

Most of those who have made estimates have complicated the issues by using sex proportions of abortions, stillbirths, or live births as indices of male mortality, instead of using male, and/or female, mortality rates. In some cases, but not in all, this has been forced on the writers by the nature of the data available. As discussed in Sections 1.1 and 4, only in limited situations are such ratios and their variations more than approximate guides to probabilities of male deaths. 
There is another possible approach to identification of the effects of harmful X-linked genes acting in utero in late foetal life. A higher mortality in females would be expected in the offspring of the two types of cousin marriage where there was a possibility of females being homozygous for the same ancestral X chromosome than in the offspring of the other two types of cousin marriage where this would not be possible. Schull and Neel (1965) could not demonstrate such a phenomenon, and Stevenson et al. (1966) could find no significant differences in mortality of female offspring of 1280 cousin marriages of the first types and those of 1513 marriages of the other two varieties.

\section{9: ESTIMATES OF MUTATION RATES TO DETRIMENTAL GENES ON THE X CHROMOSOME OF MAN}

9.1: Approaches Starting from Sex Differences in Mortality in Utero. If mutation rates on $\mathrm{X}$ chromosomes in males and females are the same and all the difference in mortality by sexes in utero over a specific period is due to recessive $\mathrm{X}$-linked mutations, then, as discussed in $\mathbf{8 . 4}$ above, one-third of the excess of male over female mortality would be an estimate of the sum of the mutation rates to harmful genes (Section 8.1). Thus for example, if the male stillbirth rate were 0.018 and that in females 0.012 , an estimate of the mutation rate would be 0.002 per $\mathrm{X}$ chromosome per generation. Consideration of the data plotted in Fig. 1 shows that on such reasoning the average mutation rate in England and Wales from 1936-1939 would be estimated to be about 0.003. From 1959 onwards, however, the estimate would be zero.

From a defined 'population of pregnancies', Frota-Pessoa and Saldanha (1960) used the data of Stevenson (1959) on the sexes of abortions, stillbirths, and live births, to develop elaborate formulae involving sex ratios. Making allowances for the numbers by sex at risk, they arrive at an estimate of a mutation rate to 'sex-linked lethals' acting in utero from the 6th menstrual week to term of 0.0068 per $\mathrm{X}$ chromosome per generation. However, from the original data one-third of the difference in the rates of loss by sex of foetuses in utero at the 6 th week is 0.0062 , and it appears that the difference between the two estimates arises from approximations and minor differences in interpretation of the data.

Tanaka (1961a,b) also arrived at an elaborate formula which calculated the mutation rate as onethird of the difference in mortality in the sexes. In his expressions he has symbols for the proportion of the excess of male over female mortality due to lethals, but as no values can be inserted these are at present of no practical importance.

These three methods, therefore, resolve to taking one-third of the difference in mortality in the sexes as an estimate of the summated mutation rate.

\section{2: Estimate of Lejeune and Turpin (1957)}

These authors correlated maternal age with the sex ratio of live births, using United States birth registration data. Fom the regression, they calculated the mutation rate at which ' $\mathrm{X}$-linked lethals' arose as 0.002 per $\mathrm{X}$ chromosome per generation. The problems of assuming that live birth sex ratios adequately reflect preceding male mortality were noted in 1.1, and it will be remembered that Novitski and Kimball (1958), who used the same data, concluded that the sex ratio of live births was unrelated to maternal age, except in so far as the latter was in turn related in a complex way to paternal age and birth order.

This estimate of Lejeune and Turpin (1957) has to be presumed to refer to mutations acting over the whole life of zygotes, as it is based on live birth sex ratios which, by implication, reflect all preceding intrauterine mortality.

\section{3: Estimates based on Correlation of Sex Ratios of Progeny with Maternal Grandfather's Age when Mother was Born}

A new method, first suggested by CavalliSforza (1961), makes use of the fact that a male's $\mathrm{X}$ chromosome always passes to his daughters, and the hypothesis that mutations arising de novo on his germ cells would accumulate, or would arise more frequently, as his age increased. It would follow that as such mutations, if recessive, would first be expressed in his daughters' sons, a positive correlation would be expected between mortality in utero of male zygotes conceived by his daughter and his age when his daughter was born. The approach has the merit that it appears to obviate problems associated with the mother's age and parity and her environment.

Cavalli-Sforza (1962a) assembled data on 60,085 women who had had at least one child, and he was able to identify their birth certificates and find the ages of their fathers when they were born. Relating the sex ratio of stillbirths to the age of the mother's father when she was born showed the positive relationship to be almost linear. The sex ratio of live births gave a negative regression. The significance of these regressions was borderline $(p=0.05$, one-tailed). The mean age of the women and the number of children they had was, however, not completely independent of the ages of the women's 
fathers when they were born, but the over-all effect of this association was very small.

Formulae were derived for calculation of mutation rates to those genes acting before and those acting after the 28th week. Assuming that the mutation rate on the $\mathrm{X}$ chromosome is the same in the sexes (or that that calculated is the average for the sexes) the total rate is estimated at $0.017 \pm 0.018$. In subsequent papers where further data were presented the results were less impressive (CavalliSforza, 1961, 1962b).

Krehbiel (1966) also uses the three-generation approach relating the maternal grandfather's age to the sex proportions of foetal deaths. As the mutation rates estimated in this interesting paper were used in UNSCEAR (United Nations, 1966) to calculate a 'total mutation rate' for man, the validity of the estimate made needs to be examined critically. It is also one of the few papers of this type where a carefully reasoned justification is given for the procedures followed. It will therefore be considered in some detail.

Krehbiel identified 6963 foetal deaths in Minnesota, which occurred in utero after the 20th week of gestation (excluding multiple births). Of these, 3693 were male and 3270 female, a sex proportion of 0.5304. By search of birth registers he found the mother's ages and those of their fathers when they were born. The birth order of the dead foetuses and other variables were also available.

Of the variables, the grandmother's age and those of the father and mother of the foetus were correlated with the grandfather's age. However, only the maternal grandmothers' ages and maternal grandfathers' ages were significantly correlated with the sex proportion of the dead foetuses. The simple regression of the sex proportions of the foetuses on grandfather's ages was $+0.0178 \pm 0.0032$ and the partial regression (neutralizing the association with the grandmothers' ages) was $0.0339 \pm 0.0085$. Both these regression coefficients are highly significant. It can be calculated from the data given by Krehbiel that the partial regression on sex pro-

TABLE V

FOETAL DEATHS ('WHITE' MOTHERS SINGLE PREGNANCIES IN MINNESOTA BY SEX AND AGE OF MATERNAL GRANDFATHERS WHEN THE MOTHERS WERE 1954-1963 Inclusive (Simplified from Krehbiel, 1966)

\begin{tabular}{c|c|c}
\hline $\begin{array}{c}\text { Grandfather's Age } \\
(\text { yr. })\end{array}$ & $\begin{array}{c}\text { No. of } \\
\text { Foetal Deaths }\end{array}$ & Sex Proportions \\
\hline $17-22$ & 365 & 0.4740 \\
$23-27$ & 1546 & 0.4994 \\
$28-32$ (mean) & 1788 & 0.5308 \\
$33-37$ & 1502 & 0.5326 \\
$38-42$ & 989 & 0.5521 \\
$43-47$ & 488 & 0.5820 \\
$48-52$ & 197 & 0.6091 \\
$53-72$ & 88 & 0.5568 \\
\hline Total & 6963 & 0.5304 \\
\hline
\end{tabular}

portions of grandchildren of the maternal grandmother's age when the mother was born (neutralizing the effects of grandfather's age $)$ is $-0.0258(p=0.02)$. This is not readily explained.

The numbers of stillbirths and the sex proportions at each mid-point of five-year intervals of maternal grandpaternal ages were as in Table V. It will be noted that in the two lowest grandpaternal age-groups there were more dead female than male foetuses. These sex proportions of foetal deaths of grandchildren of young grandfathers need explanation. There must either have been some effect stemming from having young grandfathers which increased the mortality in these female foetuses or, in the absence of X-linked lethals, female foetal death rates are higher than those in males.

Krehbiel suggests that the mutation rate in males is higher than in females, though the basis for such a supposition is entirely theoretical (Section 8.2 ). Using the regression coefficient calculated and applying it to data on live births and late foetal deaths in the State of Minnesota over the same period (which he reproduces), Krehbiel estimates as 0.00364 'the mutation rate per generation for all of the sex-linked loci capable of mutations to recessive lethals' (acting between the 20th week and birth).

In the Minnesota data the difference between foetal death rates in males $(0.0130$ per 1000 total births) and that in females $(0.0122)$ is 0.0008 per 1000 total births. If the mutation rates in the sexes were equal, a straightforward estimate of the summated mutation rate is $1 / 3 \times 0.0008=0.00027$. Even if, as Krehbiel accepts as likely, there is more mutation in males than in females, then the limiting case (Section 8.1 and Table III) is where all mutations are in males-the mutation rate on the male $\mathrm{X}$ chromosome would, on this basis, be 0.0004 . In short, estimates made in this way, from the same data, are about an order of magnitude smaller than that of Krehbiel.

\subsection{Consequences, in Terms of Expected Male Foetal Mortality, of Mutation Rates of Sizes Estimated by Various Authors}

If it is assumed that $\mathrm{X}$-linked mutations contributing to deaths of males in utero have reached equilibrium frequencies then, as shown in 8.3 above, the total mortality which would be caused by X-linked genes in equilibrium generations can be calculated for each value of the relative total mutation rates in the sexes. Krehbiel's mutation rate is calculated on the basis of a rate on male $\mathbf{X}$ chromosomes. Suppose the mutation rates in the sexes are ' $v$ ' in males and $\mu$ in females and ' $m$ ' is the mean value for any $X$ chromosome, then $\mathrm{m}=\frac{2 \mu+\mathrm{v}}{3}$. And if ' $x$ ' is the mortality determined in an equilibrium generation by mutations then $x=2 \mu+v=3 m$.

Four relative mutation rates in the sexes may be considered and for each, using Krehbiel's values calculated for male X chromosomes, the expected mortality in equilibrium generations determined by that total mutation rate can be calculated. 
(1) The mutation rates are the same in the sexes, i.e. $\mu=\mathrm{v}=\mathrm{m}$ then $\mathrm{x}=3 \mathrm{~m}=3 \times 0.00364=0.01092$.

(2) If mutation rates in the sexes are equal, but half of the new mutations arising on male $\mathrm{X}$ chromosomes are not passed to zygotes but are eliminated as spermatogonial lethals, the situation is exactly as if $\mu=2 \mathrm{v}$, then $\mathrm{x}=2 \mu+\mathrm{v}=5 \mathrm{v}=5 \times 0.00364=0.0182$.

(3) If mutation rates in males are twice as high as in females, i.e. $v=2 \mu$, then $x=2 \mu+v=2 v=2 \times 0.00364$ $=0.0073$.

(4) If there is no mutation on female $\mathrm{X}$ chromosomes, then $\mu=0$, and $\mathrm{x}=2 \mu+\mathrm{v}=\mathrm{v}=0.00364$.

As will be seen, the lowest anticipated mortality rate in the equilibrium generation for a specified mutation rate per X chromosome per generation is in (4) where no mutations occur in female $\mathrm{X}$ chromosomes. The highest anticipated mortality is in (2) where there is actually or effectively (by reason of spermatogonial lethals) a higher mutation rate in females than in males.

These predictions may now be looked at in the light of the prevailing male mortality in utero after 20 weeks over the period of Krehbiel's studies in Minnesota. The late foetal mortality rates were in males 0.0130 and in females 0.0122 ; a male excess of 0.0008 . If we presumed that the difference, 0.0008 , represented the post20 th week mortality in males due to X-linked mutations, even the lowest prediction based on Krehbiel's mutation rate estimate, i.e. where there is no mutation in males (4) is four times higher than the observed difference between the mortalities in the sexes. On assumption (1), the prediction is 13 times greater than the excess male mortality observed. Indeed the mortality which would be expected in equilibrium generations from such a mutation rate would be over $80 \%$ of mortality from all causes in males actually observed (0.013). On assumption (2), which is that taken in using Krehbiel's data in UNSCEAR (United Nations, 1966), the observed mortality would be 22 times the difference in mortality between the sexes and explains a higher male mortality than actually occurred from all causes in Minnesota.

In essence then Krehbiel's estimate of the mutation rate is an order of magnitude larger than that calculated on the basis of the difference in mortality in male and female foetuses. When therefore an excess male mortality frequency is calculated from the higher mutation rate, mortality in males is larger than that observed.

Unless subsequent experience in Minnesota is different from elsewhere, it seems likely that differences in male and female mortality will further decrease, so increasing the difficulty in reconciliation. In addition, if it is assumed that there are $\mathrm{X}$-linked mutations killing post-20th week foetuses it is just as legitimate to assume, as was done by Frota-Pessoa and Saldanha (1960), that there is a contribution to pre-20th week male mortality from X-linked mutations, and that the frequency with which they arise in males is also age dependent. If this is so, then the assumption implicit in Krehbiel's analysis that the sex proportions in utero at the beginning of the 20th week were constant for all grandfathers' ages is not valid. If the daughters of older fathers had already by the 20th week of gestation experienced relatively more male losses than the daughters of younger fathers then Krehbiel's could be an underestimate of the mutation rate determining later deaths. Finally, Krehbiel in his calculations assumes that these mutations are completely recessive, but if there is some elimination of heterozygous females then his estimate of the mutation rate on the male $\mathrm{X}$ chromosome is minimal.

These considerations all suggest that Krehbiel's approach has resulted in an overestimate of the mutation rate. That there is a significant correlation between grandpaternal ages and sex proportions in Krehbiel's data cannot be doubted even if it cannot be explained. The most likely explanation is that somehow socio-economic differences are correlated with the ages of the males when their daughters were born.

\section{0: USES MADE OF ESTIMATES OF NUMBERS OF HARMFUL MUTATIONS ARISING ON $X$ CHROMOSOME OF MAN}

Following the reasoning which Muller (1950) and others have applied to drosophila, estimates of the frequency with which mutations on the $\mathrm{X}$ chromosome arise have been used to calculate a total mutation frequency over the whole genome. The most recent estimate of such a rate is that made in UNSCEAR (United Nations, 1966) which is based on Krehbiel's estimate. The estimate is described as 'a rate per generation in male gametes of $(3 \cdot 6 \pm$ $0.9) \times 10^{-3}$ sex-linked recessive lethals acting between twenty weeks after conception and birth'. (This is not an accurate description. The rate calculated is neither to lethals nor to lethal equivalents, but is an estimate of the sum of the mutation rates of all genes contributing to deaths in this period.) The figure of $3.6 \times 10^{-3}$ is multiplied by 2 to allow for spermatogonial lethals, and by $100 / 5$ to represent the relationship of the total haploid chromosomal length to that of the X chromosome. The result is in an estimate of the total mutation rate of $0 \cdot 14$ per gamete per generation to mutations acting in utero after 20 weeks. By dividing this figure of $0 \cdot 14$ by estimated limits of spontaneous mutation rates per locus in man $\left(2 \times 10^{-5}\right.$ and $0.2 \times 10^{-5}$ ), the number of loci at which 'detectable mutations arise' is estimated in the report at between 7000 and 70,000 .

This calculation is obviously a tentative one. It must be assumed, on the evidence from other mammals, that there are many more mutations acting between conception and the 20th week than in utero after the 20th week. Further, it does not seem reasonable to assume that all action of $\mathrm{X}$ linked genes in reducing the chance of survival of 
mature foetuses stops dramatically at birth; so that if it is valid to attribute late foetal deaths to Xlinked genes then it is reasonable to suppose that a proportion of first week deaths or 'delayed stillbirths' as they are sometimes called are also so caused. Finally, we know of many visible effect $\mathrm{X}$-linked mutations manifest after birth. In short, it seems that Krehbiel's figure of 0.00364 would have to be multiplied by a factor of 2 and probably by more if it is to be used as an estimate of the rate of mutation to all genes on the $\mathrm{X}$ chromosome.

\section{1: GENERAL DISCUSSION AND SUMMARY}

Some of the many published reports on the vagaries of data on the sex proportions of live births in man have been reviewed. The degree to which many of these fluctuations are not fully explicable in the light of present knowledge has been stressed. Inevitably sex proportions of concepti of any age are determined by the primary sex ratio of zygotes as subsequently modified by any differential losses by sex. The size and range of the primary sex ratio is unknown and any estimates must be largely speculative. Nothing is known of sex proportions of periimplantation losses and what is known of sex proportions of abortions is as yet inadequate, so that it is only about those of late foetal deaths and live births that accurate information is available.

From work with experimental animals it seems clear that there are a number of prezygotic phenomena which, by reason of meiotic aberrations, result in the proportion of $\mathrm{X}$ - and $\mathrm{Y}$-bearing gametes contributing to fertilization of ova differing from an expected ratio of $1: 1$. The complications determined by sex chromosome aneuploidy in man not only raise further doubts concerning estimates of sex proportions of early losses in utero, but make it difficult to define a 'primary sex ratio'.

In view of the large number of factors associated with fluctuations in the sex proportions of foetuses in utero early and late in pregnancy in man, and the further evidence of specific modifying factors from experimental work, great care must clearly be taken in interpreting findings in respect of any group of births with unusual sex proportions (as in the offspring of irradiated parents) or fluctuations of the proportions over time, even if demonstrably associated numerically with other factors.

In the light of evidence from experimental animals it might be anticipated that in man also gene mutations determining intrauterine death would mainly act early and that their contribution to late foetal deaths would be relatively small. The rationale of methods that have been used to estimate the supposed effects of $\mathrm{X}$-linked mutations in determining late foetal mortality has been reviewed.

It is pointed out that in order to make any estimates of mutation rates many assumptions are necessary. Among the most important is the concept of equilibrium gene frequency. Another recurring assumption is that a factor considered to be affecting late foetal mortality more in males than in females does not also influence the relative mortality by sex in the earlier period of gestation.

It is pointed out that the very large changes over time of relative mortality by sex in older foetuses are impossible to reconcile with approaches to estimates of total mutation rates on the $\mathrm{X}$ chromosome, which use data from a single generation. This is because, though the methods of calculation vary, they all identify excess male over female intrauterine mortality as being due to X-linked mutations. It follows that estimates of mutation rates vary entirely with the excess male mortality. This is shown to be variable, and there are indications that when social and medical care are good male and female mortalities may be identical. It may be that, in the future, in countries with good socioeconomic standards and good medical care, late female foetal death rates will exceed those of males.

The evidence suggests that mutation rates calculated by so-called three-generation approaches are too high. These estimates, based on relationships between sex proportions of live births and/or stillbirths and maternal grandfathers' ages when the mother was born, are impossible to reconcile with late foetal mortality in males in the communities concerned.

It seems very doubtful if it is possible to define or measure any component of male mortality in utero, which is attributable to X-linked mutations. Therefore, so called mutation rates calculated may not bear any relation to what they purport to represent. It must follow that it is almost certainly fallacious to accept simple multiples of such rates as estimates of 'total mutation rates over the genome'.

We are indebted to the Health Physics Society, the publishers, Pergamon Press, and the International Commission on Radiological Protection, for permission to reproduce Tables I and II; and to the author Dr. E. L. Krehbiel and the publishers, Messrs. Grune and Stratton, Inc., for permission to reproduce the data in Table $\mathbf{V}$ from An estimatiod of the cumulative mutation rate for sex-linked lethals in man which produce fetal deaths, in the Amer. F. hum. Genet., Vol. 18, 127-143, 1966. Figure 3 is reprinted from The sex ratio of stillbirths related to cause and duration of gestation; investigation of 7,066 stillbirths, in Hum. Biol., Vol. 23, 
No. 1, 41-60, 1951, by T. McKeown and C. R. Lowe, by permission of the Wayne State University Press. Professor K. G. Lüning has kindly allowed us to quote from his memoranda to the United Nations Scientific Committee on the Effects of Atomic Radiation.

We have to thank our colleague Mr. M. Oakes for many helpful discussions and for good advice in preparing this review.

\section{REFERENCES}

Abrahamson, S., Meyer, H. U., Himoe, E., and Daniel, G. (1966). Further evidence demonstrating germinal selection in early premeiotic germ cells of Drosophila males. Genetics, 54, 687.

Allan, T. M. (1955). Blood-groups and reproduction. Lancet, 2, 94.

(1958). Rh blood groups and sex ratio at birth. Brit. med. F., 2, 248.

(1959). ABO blood groups and sex ratio at birth. ibid., 1, 553

Andreassen, M. (1943). Haemofili i Danmark. En klinisk, haematologisk og arvebiologisk undersøgelse af 63 haemofilislaegter. Op. Domo Biol. hered. hum. Kbh., Vol. 6.

Auerbach, C. (1954). Sensitivity of the Drosophila testis to the mutagenic action of $x$-rays. $Z$. indukt. Abstamm.-u. Vererb.-L., 86, 113.

(1962). Mutation, Part I. Oliver and Boyd, Edinburgh and London.

- Falconer, D. S., and Isaacson, J. H. (1962). Test for sexlinked lethals in irradiated mice. Genet. Res., 3, 444.

Barr, A., and Stevenson, A. C. (1961). Stillbirths and infant mortality in twins. Ann. hum. Geret., 25, 131.

Bianchi, N. O., and Bianchi, M. S/ A. de (1966). Technique for investigation of sex chromatin in amniotic membrane of rat foetuses. Nature (Lond.), 212, 1593.

Bittner, J. J. (1936). Differences observed in an inbred albino strain of mice following a change in diet. II. Mortality. Nutr. Bull. No. 2, Fackson Mem. Lab. Bar Harbor, p. 3.

Braden, A. W. H. (1958). Influence of time of mating on the segregation ratio of alleles at the ' $\mathrm{T}$ ' locus in the house mouse. Nature (Lond.), 181, 786 .

Carr, D. H. (1966). Communication of data reproduced in United Nations Scientific Committee on the Effects of Atomic Radiation, 1966.

Carter, T. C. (1959). A pilot experiment with mice, using Haldane's method for detecting induced autosomal recessive lethal genes. f. Genet., 56, 353.

Catcheside, D. G. (1948). Genetic effects of radiation. Advanc. Genet., 2, 271.

, and Lea, D. E. (1945). The rate of induction of dominant lethals in Drosophila melanogaster sperm by $x$-rays. $\mathcal{f}$. Genet., 47, 1.

Cattanach, B. M. (1962). XO mice. Genet. Res., 3, 487.

Cavalli-Sforza, L. L. (1961). Un metodo perlastima della frequenza di mutazione nell'uomo: Risultati preliminare. Atti. Ass. genet. ital., 6, 151 .

- (1962a). Demographic attacks on genetic problems: Some possibilities and results. In The Use of Vital and Health Statistics or Genetic and Radiation Studies (A/AC.82/Seminar), p. 221. United Nations, New York.

- (1962b). Indagine speciale su alcune caratteristiche genetiche della popolazione Italiana. Note e Relationi, Institituto Centrale di Statistica (Roma) N. 17, 9.

Chapman, A. B., Hansen, J. L., Havenstein, G. B., and Morton, N. E. (1964). Genetic effects of cumulative irradiation on prenatal and early post-natal survival in the rat. Genetics, 50, 1029.

Charles, D. R. (1950). Radiation-induced mutations in mammals. Radiology, 55, 579.

Cheeseman, E. A., Kilpatrick, S. J., Stevenson, A. C., and Smith C. A. B. (1958). The sex ratio of mutation rates of sex-linked recessive genes in man with particular reference to Duchenne type muscular dystrophy. Ann. hum. Genet., 22, 235.

Ciocco, A. (1938). Variation in the sex ratio at birth in the United States. Hum. Biol., 10, 36.

Cohen, B. H., and Glass, B. (1956). The ABO blood groups and the sex ratio. ibid., 28,20

- and - (1959). Further observations on the ABO blood groups and the sex ratio. Amer. F. hum. Genet., 11, 274.
Counce, S. J., and Poulson, D. F. (1962). Developmental effects of the sex-ratio agent in embryos of Drosophila willistoni. $\mathcal{F}$. exp. Zool., 151, 17.

Crew, F. A. E. (1948). Measurements of the Public Health. Oliver and Boyd, Edinburgh and London.

Csordás, T., Dömötöri, E., Gergely, E., and Rechnitz, K. (1963) Úber die Geschlechtsproportion der Früchte in den ersten 3 Monaten des intrauterinen Lebens. Zbl. Gynäk., 85, 1036.

Edwards, A. W. F. (1958). An analysis of Geissler's data on the human sex ratio. Ann. hum. Genet., 23, 6.

- (1961). The population genetics of 'sex ratio' in Drosophila pseudoobscura. Heredity, 16, 291.

- and Fraccaro, M. (1958). The sex distribution in the offspring of 5,477 Swedish ministers of religion 1585-1920. Hereditas (Lund), 44, 447.

, and - (1960). Distribution and sequences of sexes in a selected sample of Swedish families. Ann. hum. Genet., 24, 245.

Edwards, J. H. (1957). A critical examination of the reputed primary influence of ABO phenotype on fertility and sex ratio. Brit. F. prev. soc. Med., 11, 79.

Fano, V. (1941). On the analysis and interpretation of chromosomal changes in Drosophila. Cold Spr. Harb. Symp. quant. Biol., 9, 113.

Friedman, L. D. (1964). $X$-ray induced sex-linked lethal and detrimental mutations and their effect on the viability of Drosophila melanogaster. Genetics, 49, 689.

Frota-Pessoa, O., and Saldanha, P. H. (1960). The rate of spontaneous sex-linked mutations and the doubling dose in man Ann. hum. Genet., 24, 367.

Gates, W. H. (1930). The effect of polygyny on the sex ratio of mice (Mus musculus). 7. exp. Biol., 7, 235.

Geissler, A. (1889). Beiträge zur Frage des Geschlechtsverhältnisses der Geborenen. Z Z sächs. statist. Bur., 35, 1.

Gershenson, S. (1928). A new sex-ratio abnormality in Drosophila obscura. Genetics, 13, 488 .

Glenister, T. W. (1956). Determination of sex in early human embryos. Nature (Lond.), 177, 1135.

Goodhart, C. B. (1964). The frequency of illegal abortion. Eugen. Rev., 55, 197.

Grahn, D., Verley, F. A., and Leslie, W. P. (1966). Preliminary report: determination of the radiation induced mutation rate for sex-linked lethals in the mouse. Genetics, 54, 336.

Gruneberg, H. (1952). The Genetics of the Mouse, 2nd ed. M. Nijhoff, The Hague.

Hahn, E. W., and Hays, R. L. (1963), Modification of the secondary sex ratio in the albino rat by progesterone and oestrogen therapy. F. Reprod. Fertil., 6, 409.

Haldane, J. B. S. (1935). The rate of spontaneous mutation of a human gene. f. Genet., 31, 317 .

- (1947). The mutation rate of the gene for haemophila, and its segregation ratios in males and females. Ann. Eugen. (Lond.), 13, 262.

- (1956). Mutation in the sex-linked recessive type of muscular dystrophy. A possible sex difference. Ann. hum. Genet., 20, 344 .

Hammond, J. (1934). The fertilization of rabbit ova in relation to time. F. exp. Biol., 11, 140.

Hanks, G. D. (1965). Are deviant sex ratios in normal strains of Drosophila caused by aberrant segregation. Genetics, 52, 259.

- (1966). Genetic analysis of a normal deviant sex ratio in Drosophila melanogaster. ibid., 54, 338.

Hart, D., and Moody, J. D. (1949). Sex ratio: experimental studies demonstrating controlled variations-preliminary report. Ann. Surg., 129, 550.

Hertwig, P. (1938). Unterscheide in der Entwicklungsfähigkeit von F 1 Mäusen nach Röntgen-bestrahlung von Spermatogonien, fertigen und unfertigen Spermatozoen. Biol. Zbl., 58, 273.

Hewitt, D., Webb, J. W., and Stewart, A. M. (1955). A note on the occurrence of single-sex sibships. Ann. hum. Genet., 20, 155.

Hickey, W. A., and Craig, G. B. (1966). Genetic distortion of sex ratio in a mosquito, Aedes aegypti. Genetics, 53, 1177.

Hirszfeld, L., and Zborowski, H. (1925). Gruppenspezifische Beziehungen zwischen mutter und Frucht und elektive Durchlässigkeit der Placenta. Klin. Wschr., 4, 1152.

Howard, A., McLaren, A., Michie, D., and Sander, G. (1955). Genetic and environmental influences on the secondary sex ratio in mice. F. Genet., 53, 200.

Kafer, E. (1952). Vitalitätsmutationen: Ausgelöst durch Röntgenstrahlen bei Drosophila melanogaster. Z. indukt. Abstamm.-u. Vererb.-L., 84, 508. 
Kalmus, H., Metrakos, J. D., and Silverberg, M. (1952). Sex ratio of offspring from irradiated male mice. Science, 116, 274.

Kaplan, I. I. (1957). The treatment of female sterility with $x$-rays to the ovaries and the pituitary, with special reference to congenital anomalies of the offspring. Canad. med. Ass. F., 76, 43.

Kerkis, I. (1935). The preponderance of 'physiological mutations'. Summ. Commun. 15th int. physiol. Congr., p. 198.

King, H. D. (1918). Studies on inbreeding. III. The effect of inbreeding, with selection, on the sex ratio in the albino rat. $f$. exp. Zool., 27, 1.

Kohn, H. I. (1960). The effect of paternal $x$-ray exposure on the secondary sex ratio in mice ( $F 1$ generation). Genetics, 45, 771 .

Krehbiel, E. L. (1966). An estimation of the cumulative mutation rate for sex-linked lethals in man which produce fetal deaths. Amer. F. hum. Genet., 18, 127.

Lanier, G. N., and Oliver, J. H., Jr. (1966). 'Sex ratio' condition: unusual mechanisms in Bark beetles. Science, 153, 208.

Lejeune, J., and Turpin, R. (1957). L'influence de l'age des parents sur la masculinité de naissances vivantes. C. R. Acad. Sci. (Paris), 244, 1833.

$\longrightarrow,-$, and Rethore, M. O. (1960). Les enfants nes de parents irradies (cas particuliers de la sex-ratio). Proc. IX int. Congr. Radiol., Munich, 1959, p. 1089.

Lüning, K. G. (1962). Sex-ratio: an unreliable method for estimations of radiation hazards. UN Document A/AC82/G/L671.

- (1964). Studies of irradiated mouse populations. III Accumulation of recessive lethals. Mutat. Res., 1, 86.

, and Sheridan, W. (1964). Dominant effects on productivity in offspring of irradiated mouse populations. Genetics, 50, 1043.

Lyon, M. F., Phillips, R. J. S., and Searle, A. G. (1964). The overall rates of dominant and recessive lethal and visible mutation induced by spermatogonial $\mathrm{x}$-irradiation of mice. Genet. Res., $\mathbf{5}$, 448.

Macht, S. H., and Lawrence, P. S. (1955). National survey of congenital malformations resulting from exposure to roentgen radiation. Amer. F. Roentgenol., 73, 442.

McKeown, T., and Lowe, C. R. (1951). The sex ratio of stillbirths related to cause and duration of gestation: an investigation of 7,066 stillbirths. Hum. Biol., 23, 41.

McMahon, B., and Pugh, T. F. (1954). Sex ratio of white births in the United States during the second World War. Amer. F. hum. Genet., 6, 284.

McWhirter, K. G. (1956). Control of sex ratio in mammals. Nature (Lond.), 178, 870.

Malogolowkin, Ch., and Poulson, D. F. (1957). Infective transfer of maternally inherited abnormal sex-ratio in Drosophila willistoni. Science, 126, 32.

Malpas, P. (1938). A study of abortion sequences. F. Obstet. Gynaec. Brit. Emp., 45, 932.

Moore, C. R., and Price, D. (1948). A study at high altitude of reproduction, growth, sexual maturity and organ weights. $f$. exp. Zool., 108, 171.

Moore, K. L., and Barr, M. L. (1954). Nuclear morphology, according to sex, in human tissues. Acta. anat. (Basel), 21, 197.

Morton, N. E., Crow, J. F., and Muller, H. J. (1956). An estimate of the mutational damage in man from data on consanguineous marriages. Proc. nat. Acad. Sci. (Wash.), 42, 855.

Muller, H. J. (1945). Age in relation to the frequency of spontaneous mutations in Drosophila. Yb. Amer. phil. Soc., 150.

(1950). Our load of mutations. Amer. F. hum. Genet., 2, 111. (1954). The nature of the genetic effects produced by radiation. The manner of production of mutations by radiation. In Radiation Biology, ed. Alex. Hallaender, Vol. I, Part I, pp. 351 and 475. McGraw Hill, New York.

Neel, J. V. (1957). Some problems in the estimation of spontaneous mutation rates in animals and man. In Effect of Radiation on Human Heredity, p. 139 . World Health Organization, Geneva.

- (1963). Changing Perspectives on the Genetic Effects of Radiation. C. C. Thomas, Springfield.

, and Schull, W. J. (1956). The Effect of Exposure to the Atomic Bombs on Pregnancy Termination in Hiroshima and Nagasaki. (Publ. 461.) Nat. Acad. Sci.-Nat. Res. Counc., Washington.

Novitski, E. (1953). The dependence of the secondary sex ratio in humans on the age of the father. Science, 117,531 .

-, and Kimball, A. W. (1958). Birth order, parental ages, and sex of offspring. Amer. F. hum. Genet., 10, 268.

- and Sandler, L. (1956). The relationship between parental age, birth order and the secondary sex ratio in humans. Ann. hum. Genet., 21, 123.
, and - (1957). Are all products of spermatogenesis regularly functional? Proc. nat. Acad. Sci. (Wash.), 43, 318.

Parkes, A. S. (1925). The effects on fertility and the sex-ratio of sub-sterility exposures to $x$-rays. Proc. roy. Soc. $B, 98,415$.

- (1926). The physiological factors governing the proportions of the sexes in man. Eugen. Rev., 17, 275.

Peacock, W. J., and Erickson, J. (1965). Segregation-distortion and regularly nonfunctional products of spermatogenesis in Drosophila melanogaster. Genetics, 51, 313.

Race, R. R. (1965). Identification of the origin of the X-chromosome(s) in sex chromosome aneuploidy. Canad. F. Genet. Cytol., $7,214$.

Renkonen, K. O. (1956). Is the sex ratio between boys and girls correlated to the sex of precedent children? Ann. Med. exp. Fenn., 34, 447.

Russell, L. B., and Saylors, C. L. (1963). The relative sensitivity of various germ cell stages of the mouse to radiation-induced nondisjunction, chromosome losses and deficiencies. In Repair from Genetic Radiation Damage, ed. F. H. Sobels, p. 313. Pergamon Press, Oxford.

Russell, W. L. (1954). Genetic effects of radiation in mammals. In Radiation Biology, ed. Alex. Hollaender, Vol. I, Part 2, p. 825. McGraw Hill, New York.

Russell, W. T. (1936). Statistical study of the sex ratio at birth. F. Hyg. (Lond.), 36, 381

Sanghvi, L. D. (1951). ABO blood groups and sex-ratio at birth in man. Nature (Lond.), 168, 1077.

Sawin, P. B., and Gadbois, D. S. (1947). Genetic influences upon the sex ratio in the rabbit. Genetics, 32, 286.

Scholte, P. J. L., and Sobels, F. H. (1964). Sex ratio shifts among progeny from patients having received therapeutic $\mathrm{X}$-radiation. Amer. F. hum. Genet., 16, 26.

Schull, W. J., and Neel, J. V. (1958). Radiation and the sex ratio in man. Science, 128, 343.

, and - (1965). The Effects of Inbreeding on Fapanese Children. Harper and Row, New York.

Schultz, A. H. (1918). Studies in the sex-ratio in man. Biol. Bull. mar. biol. Lab., Woods Hole, 34, 257.

Schultze, K. W. (1961). Geschlects-bestimmungen bei Aborten verschiedener Genese. Zbl. Gynäk., 83, 56.

Schützenberger, M. P. (1949). Résultats d'une enquête sur la distribution de sexe dans les familles nombreuses. Sem. Hôp. Paris, 25, 2579.

Searle, A. G. (1964). Genetic effects of spermatogonial X-irradiation on productivity of F 1 female mice. Mutat. Res., 1, 99.

Serr, D. M., and Ismajovich, B. (1963). Determination of the primary sex ratio from human abortions. Amer. f. Obstet. Gynec., 87, 63.

Shapiro, B. A. (1936). Is there germ cell selection in Drosophila melanogaster. Dokl. Akad. Nauk SSSR (for. Lang. Edn., NS2,) 119.

Shield, J. W., Kirk, R. L., and Jakobowicz, R. (1958). The ABO blood groups and masculinity of offspring at birth. Amer. $\mathrm{F}$. hum. Genet., 10, 154.

Slatis, H. M. (1953). Seasonal variation in the American live birth sex ratio. ibid., $5,21$.

Snell, G. D., and Ames, F. B. (1939). Hereditary changes in the descendants of female mice exposed to Roentgen rays. Amer. $\mathcal{F}$. Roentgenol., 41, 248.

Sonnernlick, B. P. (1940). Cytology and development of the embryos of $x$-rayed adult Drosophila melanogaster. Proc. nat. Acad. Sci. (Wash.), 26, 373.

Stern, C. (1960). Principles of Human Genetics, 2nd ed. W. H. Freeman, San Francisco.

Stevenson, A. C. (1957). Achondroplasia: an account of the condition in Northern Ireland. Amer. F. hum. Genet., 9, 81 . - (1958). Muscular dystrophy in Northern Ireland. IV. Some additional data. Ann. hum. Genet., 22, 231.

(1959). Observations on the results of pregnancies in women resident in Belfast. III. Sex ratio with particular reference to nuclear sexing of chorionic villi of abortions. Ann. hum. Genet., 23, 415.

(1962). The sex ratio at conception. Evidence from nuclear sexing of chorionic villi of abortions. Acta cytol. (Philad.), 6 , 116.

(1966). Sex chromatin and the sex ratio in man. In The Sex Chromatin, ed. K. L. Moore, p. 263. W. B. Saunders, Philadelphia. 
-, Dudgeon, M. Y., and McClure, H. I. (1959). Observations on the results of pregnancies in women resident in Belfast. II. Abortions, hydatiform moles and ectopic pregnancies. Ann. hum. Genet., 23, 395.

, Johnston, H. A., Stewart, M. I. P., and Golding, D. R. (1966). Congenital malformations: A report of a study of series of consecutive births in 24 centres. Bull. Wld Hlth Org., 34, Suppl.

, and McClarin, R. H. (1957). Determination of the sex of human abortions by nuclear sexing the cells of the chorionic villi. Nature (Lond.), 180, 198.

- , and Warnock, H. A. (1959). Observations on the results of pregnancies in women resident in Belfast. I. Data relating to all pregnancies ending in 1957. Ann. hum. Genet., 23, 382.

Strandskov, H. H., and Bisaccia, H. (1949). The sex ratio of human stillbirths at each month of uterogestation and at conception. Amer. F. phys. Anthrop., 7, 131.

Sturtevant, A. H., and Dobzhansky, T. (1936). Geographical distribution and cytology of 'sex-ratio' in Drosophila pseudoobscura and related species. Genetics, 21, 473.

Szontagh, F. E., Jakobovits, A., and Mehes, C. (1961). Primary embryonal sex ratio in normal pregnancies determined by nuclear chromatin. Nature (Lond.), 192, 476.

Tanaka, K. (1961a). Genetic effects of chronic ionizing radiation on man. Proc. 2nd Int. Congr. hum. Genet., 2, 1234.

$-(1961 \mathrm{~b})$. Estimation of radiation induced mutation rates in man. fap. F. Genet., 36, Suppl. 42.

Timofeeff-Ressovsky, N. W. (1935). Auslösung von Vitalitatsmutationen durch Röntgenbestrahlung bei Drosophila melanogaster. Nachr. Ges. Wiss. Gottingen Math. Physik. Kl. Biol., NF 1, 163.

Trasler, D. G., and Metrakos, J. D. (1953). Sex ratio of offspring from irradiated male mice. Genetics, 38, 697.

Tschuprow, A. (1915). Zur Frag des sindkenden. Knabenüberschusses unter den ehelich Geborenen. Bull. Inst. int. Statist., 20, 378.
Turpin, R., Lejeune, J., and Rethore, M. O. (1956). Etude de la descendance de sujets traités par radiothérapie pelvienne. Acta genet. (Basel), 6, 204.

Twiesselmann, F., Defrise-Gussenhoven, E., and Leguebe, A. (1962). Incidence on genetics of mechanisms of segregation and disjunction at meiosis in man. Nature (Lond.), 196, 1232.

United Nations (1959). Demographic Year Book, 11th issue. New York.

- (1962). Report of the United Nations Scientific Committee on the Effects of Atomic Radiation, General Assembly, Official Records, 17th Session, Suppl. 16 (A/5216).

- (1966). Report of the United Nations Scientific Committee on the Effects of Atomic Radiation, General Assembly, Official Records, 21 st Session, Suppl. 14 (A/6314).

Warburton, D., and Fraser, F. C. (1964). Spontaneous abortion risks in man: data from reproductive histories collected in a medical genetics unit. Amer. F. hum. Genet., 16, 1.

Waterhouse, J. A. H., and Hogben, L. (1947). Incompatibility of mother and foetus with respect to the iso-agglutinogen $A$ and its antibody. Brit. F. prev. soc. Med., $1,1$.

Weir, J. A. (1953). Association of blood-pH with sex ratio in mice. f. Hered., 44, 133.

- (1955). Male influence on sex ratio of offspring in high and low blood-pH lines of mice. ibid., 46, 277.

- (1962). Hereditary and environmental influences on the sex ratio of $\mathrm{PHH}$ and $\mathrm{PHL}$ mice. Genetics, 47, 881.

Wilson, K. M. (1926). Correlation of external genitalia and sex glands in the human embryo. Contr. Embryol. Carneg. Instn, $18,23$.

World Health Organization (1966). Standardization of procedures for chromosome studies in abortion. Report of a Study Group. Bull Wld Hlth Org., 34, 765.

\section{Corrigenda}

Agar Diffusion Test for Serum Cholinesterase Typing and Influence of Temperature on Dibucaine and Fluoride Numbers; by George Lee and J. C. Robinson. Vol. 4, No. 1 (March 1967).

The authors regret the following errors:

Page 21. The mean of Fluoride Numbers of 84 I individuals obtained by Harris and Whittaker (1961) in Table III should read 47.79 (not 44.79).

Page 24. First inhibition number in Table VI should read $\mathrm{FN}$ (not DN). 